\title{
Zebra GC: A Fully Integrated Micro Gas Chromatography System
}

\author{
Apoorva Garg
}

Thesis submitted to the faculty of the Virginia Polytechnic Institute and State University in partial fulfillment of the requirements for the degree of

\author{
Master of Science \\ In \\ Computer Engineering \\ Masoud Agah, Co-Chair \\ Leyla Nazhandali, Co-Chair \\ Linsey C. Marr
}

July 11, 2014

Blacksburg, Virginia

Keywords: Micro Gas Chromatography, Environmental Monitoring, Embedded Systems 


\section{Zebra GC: A fully integrated micro gas chromatography system}

Apoorva Garg

\section{ABSTRACT}

A ready-to-deploy implementation of microfabricated gas chromatography $(\mu \mathrm{GC})$ system characterized for detecting hazardous air pollutants (HAPs) at parts-per-billion (ppb) concentrations in complex mixtures has been described. A microfabricated preconcentrator $(\mu \mathrm{PC})$, a MEMS separation column with on-chip thermal conductivity detector $(\mu \mathrm{SC}$ TCD), the flow controller unit, and all the necessary flow and thermal management as well as user interface circuitry are integrated to realize the fully functional $\mu \mathrm{GC}$ system. The work reports extensive characterization of $\mu \mathrm{PC}, \mu \mathrm{SC}$ and $\mu \mathrm{TCD}$ for target analytes: benzene, toluene, tetrachloroethylene, chlorobenzene, ethylbenzene, and $p$-xylene. Limit of Detection (LOD) of $\sim 1 \mathrm{ng}$ was achieved, which corresponds to 10 min sampling time at a flow rate of $1 \mathrm{~mL} / \mathrm{min}$ for analyte present at $\sim 25 \mathrm{ppbv}$ concentration. An innovative method for generating very sharp injection plugs from the $\mu \mathrm{PC}$ even in the presence of flow sensitive detectors like $\mu \mathrm{TCD}$ is described. A one-to-one comparison between $\mu \mathrm{GC}$ system and conventional Automated Thermal Desorption-Gas Chromatograph-Flame Ionization Detector (ATD GC-FID) system for real gasoline samples in simulated car refueling scenario is reported. 


\section{Acknowledgements}

I would like to take this opportunity to express my gratitude to several individuals for their support of my graduate studies at Virginia Tech.

Firstly, I extend sincere thanks to my research advisor, Dr. Masoud Agah, for giving me an opportunity to work in VT MEMS lab. His vision and objective approach to work has inspired me immensely. I'm grateful for his guidance, support and patience throughout the project. I would like to express my sincere gratitude to Dr. Leyla Nazhandali for her valuable inputs and guidance during the course of project.

Dr. Linsey Marr, for providing the platform to evaluate the system developed and for agreeing to serve on my thesis committee.

My lab mates: Shree Narayana, for introducing me to the project, his continued help in figuring out the design details and answering my endless list of questions. Muhammad Akbar, for helping me in characterizing and testing the system. Eric Vejerano, for helping with his expertise in analytical chemistry and environmental monitoring. Hamza Shakeel, for all gas chromatography related discussions. Harmish Modi, for developing the Labview application. I would also like to thank the other lab members for creating a friendly and supporting environment.

I express my sincere gratitude to my parents and family for keeping faith in me and in their willingness to let me come forward for this step in my career.

Finally, I would like to thank the National Institute for Occupational Safety and Health for supporting this work under Award No. 1R21OH010330. 


\section{Contents}

1. Introduction 1

1.1 Contributions 5

1.2 Organization of Thesis 5

2. Background and Motivation $\quad 7$

2.1 Conventional GC systems 7

$2.2 \mu \mathrm{GC}$ Systems 9

$\begin{array}{lll}2.2 .1 & \text { Injector } & 10\end{array}$

2.2.2 Separation Column 11

$\begin{array}{lll}2.2 .3 & \text { Detectors } & 11\end{array}$

2.2.4 Flow Control 11

2.3 Application of GC for environment monitoring 12

3. Zebra GC System Architecture, Design and Operation 13

3.1 Microfabricated Components 13

3.1.1 $\mu \mathrm{PC}$ chip $\quad 15$

$\begin{array}{lll}3.1 .2 \mu \mathrm{SC}-\mathrm{TCD} & 16\end{array}$

3.2 Integrated electronic module 17

$\begin{array}{lll}3.2 .1 & \text { Valve control } & 18\end{array}$

$\begin{array}{ll}\text { 3.2.2 Pump control } & 19\end{array}$

$\begin{array}{lll}\text { 3.2.3 Temperature controller } & 20\end{array}$

3.2.4 $\mu$ TCD Interface 21

3.2.5 Human Machine Interface and Data Acquisition 21

3.3 System Integration and Operation 22

$\begin{array}{lll}\text { 3.3.1 Loading } & 24\end{array}$ 
$\begin{array}{lll}\text { 3.3.2 Injection } & 25\end{array}$

$\begin{array}{lll}\text { 3.3.3 Analysis } & 25\end{array}$

$\begin{array}{lll}3.3 .4 & \text { Cleaning } & 26\end{array}$

4. Zebra GC System Implementation 27

$\begin{array}{lll}4.1 & \text { Early prototypes } & 27\end{array}$

4.2 Zebra GC System 29

4.2.1 $\mu$ Fluidic Module 29

4.2.2 Integrated Electronic Module 30

4.2.3 Embedded Firmware 31

4.2.4 Labview Application 32

5. Results and Discussions 34

5.1 Integrated Electronic Module Testing 34

$5.2 \mu \mathrm{PC}$ Testing $\quad 37$

$\begin{array}{lll}\text { 5.2.1 Adsorption capacity } & 38\end{array}$

$\begin{array}{lll}\text { 5.2.2 } & \text { Breakthrough volume (BV) } & 40\end{array}$

5.2.3 Desorption peak width and desorption efficiency 40

$5.3 \mu \mathrm{SC}-\mathrm{TCD}$ Testing $\quad 41$

5.4 Integration of $\mu \mathrm{PC}$ and $\mu \mathrm{SC}-\mathrm{TCD}$

5.5 Microsystem Testing, Calibration and Evaluation 44

$\begin{array}{llr}\text { 6. Conclusion } & 48\end{array}$

$\begin{array}{lll}6.1 & \text { Future Work } & 48\end{array}$

$\begin{array}{ll}\text { References } & 50\end{array}$ 


\section{List of Figures}

Figure 2-1 Schematic diagram and photograph of a GC system (Photo by Apoorva Garg, 2014) 8

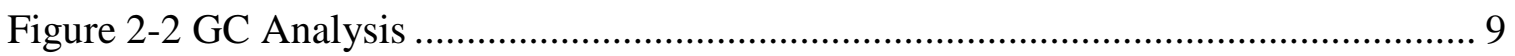

Figure 2-3 Schematic diagram of $\mu \mathrm{GC}$ system............................................................. 10

Figure 3-1: Process flow for the fabrication of $\mu \mathrm{PC}$ and $\mu \mathrm{SC}-\mathrm{TCD}$............................... 14

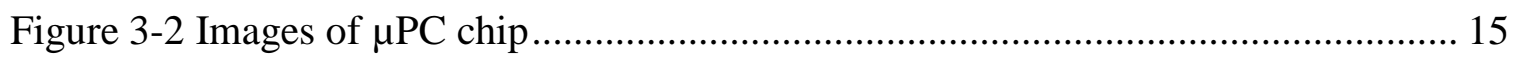

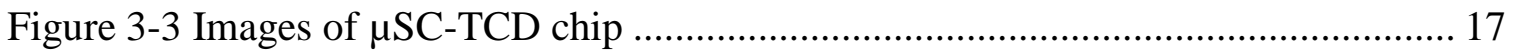

Figure 3-4 Integrated Electronic Module.................................................................. 18

Figure 3-5 Valve Control Circuit Diagram ................................................................. 19

Figure 3-6 Pump Control Circuit Diagram ................................................................... 19

Figure 3-7 Temperature Controller Circuit Diagram................................................... 20

Figure 3-8 $\mu$ TCD Interface Circuit Diagram .............................................................. 21

Figure 3-9 Data Acquisition Interface Circuit Diagram …………………………….... 22

Figure 3-10 Zebra GC Schematic Diagram ............................................................... 23

Figure 3-11 Timing Diagram .............................................................................. 24

Figure 3-12 Loading Stage Flow Diagram ………………………………………..... 24

Figure 3-13 Injection Stage Flow Diagram …………………................................ 25

Figure 3-14 Cleaning Stage Flow Diagram ............................................................ 26

Figure 4-1 Arduino UNO based prototype (Photo by Apoorva Garg, 2014) ................... 28

Figure 4-2 Arduino MEGA Shield for $\mu$ GC system (Photo by Apoorva Garg, 2014).... 28

Figure 4-3 Zebra GC prototype (Photo by Apoorva Garg, 2014)...................................... 29

Figure 4-4 $\mu$ Fluidic Module (Photo by Apoorva Garg, 2014) .......................................... 30

Figure 4-5 Integrated Electronic Module (Photo by Apoorva Garg, 2014)...................... 31

Figure 4-6 Embedded Firmware Pseudo Code ………………………………………... 32

Figure 4-7 Screenshot of Labview Application ............................................................... 33

Figure 5-1 $\mu \mathrm{PC}$ temperature profile and effect of heater voltage on $\mu \mathrm{PC}$ heating ........... 35

Figure 5-2 $\mu \mathrm{SC}$ temperature profile for ramp rate $20^{\circ} \mathrm{C} / \mathrm{min}$ and $30^{\circ} \mathrm{C} / \mathrm{min}$................... 36

Figure 5-3 $\mu \mathrm{PC}$ sample capacity and breakthrough volume............................................ 39 


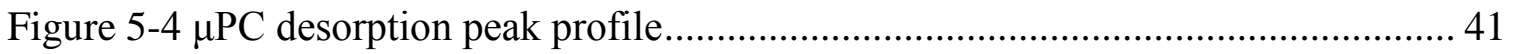

Figure 5-5 Minimum detectable limit (MDL) for test compounds by $\mu$ TCD ................. 43

Figure 5-6 Separation of test compounds with integrated $\mu \mathrm{PC}$ and $\mu \mathrm{SC} \ldots \ldots \ldots \ldots \ldots \ldots . . . . . . . . . . . .44$

Figure 5-7 Chromatogram of (A) gasoline vapor and (B) standards using $\mu \mathrm{GC}$........... 45

Figure 5-8 Chromatogram of gasoline vapor (green) and standards ............................. 47 


\section{List of Tables}

Table 1-1 Summary and comparison of $\mu \mathrm{GC}$ systems .............................................. 4

Table 5-1 $\mu$ PC Average Ramp Rate and Power Consumption ...................................... 36

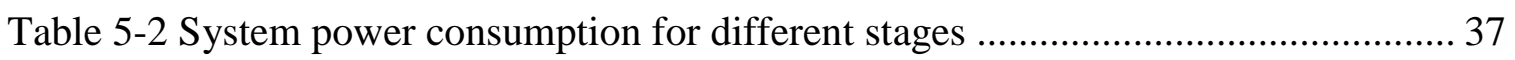




\section{Introduction}

Hazardous air pollutants (HAPs), such as aromatic compounds and polycyclic aromatic hydrocarbons have serious environmental and health effects that are implicated with a variety of diseases in humans ranging from birth defects to cancer [1]. Toxic volatile organic compounds (VOCs) such as benzene and toluene found in gasoline, and xylene used in ink, rubber and leather industries are of concern as they are present at elevated concentration due to their higher vapor pressure. Sufficient exposure to these toxicants, even at lower concentration like 100 ppbv, may cause adverse health effects. Most of these pollutants emerge from man-made sources and activities: emissions from automobile, refineries, factories, and power plants. To safeguard the health of exposed individuals and to ensure that the concentrations of these VOCs do not exceed the permissible exposure levels set through federal regulations, it is critical to monitor both qualitatively and quantitatively the emissions of VOCs.

Among various analytical methods, gas chromatography (GC) has been the established method for assessing the presence and concentration of VOCs in the environment, and GC coupled to mass spectrometry (GC-MS) is one of the most accurate and widely used tool. In this technique, samples are first collected from the field through trap based system such as sorbent tubes or canister and then are analyzed in a laboratory by trained technicians. Such methods require manual intervention and multiple steps, like sampling, storage and shipping, before analysis and therefore are susceptible to higher losses and have longer 
measurement cycles. Most of these drawbacks can be overcome by using portable, fielddeployable, and real-time detection systems. There are attempts at miniaturizing GC-MS systems [2, 3], but such systems are still bulky, expensive, and consume high amount of power. Other real-time detection techniques involve using sensitive photo-ionization detector (PID) [4] to realize a total VOC analyzer. PID based systems suffer from selectivity issues and require filtering at source which renders them ineffective and expensive for multi-compound analysis. Colorimetric tubes [5] are another inexpensive and popular technique for VOC analysis which relies on color change induced by the irreversible reaction between the sensing material and the analyte. However, this technique requires human intervention, and its use is limited by the slow response and higher uncertainty in sensitivity towards other compounds. A more comprehensive solution for detection of VOC is based on portable gas chromatography systems leveraging microfabricated components to achieve a small form factor, low power consumption, selectivity, and high sensitivity. Several commercial high performance portable gas chromatography systems [6, 7] have been reported, but they are still bulky, energy inefficient, and expensive for real-time environmental monitoring applications. Such system limitations can be addressed to a reasonable extent by making them more application specific and using lower cost batch-fabricated micro components.

Currently, considerable research efforts in the development of micro-gas chromatography $(\mu \mathrm{GC})$ systems are directed towards developing and optimizing high-performance microfabricated components such as preconcentrators $(\mu \mathrm{PC})$ [8-10], separation column ( $\mu \mathrm{SC})$ [11-13], and gas detectors [14-17]. However, integration of the various components is a critical yet underexplored aspect.

In this work, we present an innovative $\mu \mathrm{GC}$ architecture, which leverages monolithic integration of separation column with micro-thermal conductivity detectors ( $\mu$ SC-TCD) [18] to minimize band broadening and chip-to-chip fluidic interfaces. The integration eliminates the need for a reference line and requires less number of external components. Further innovative aspects of this architecture include a method to perform very sharp injections from the $\mu \mathrm{PC}$ even in the presence of flow-sensitive gas detectors like TCD. This 
innovative system design relaxes constraints on the design of the $\mu \mathrm{PCs}$ by mitigating the effect of vapor desorption time on the injection-plug width. The design enables us to achieve low detection limits suitable for environmental monitoring applications. We report in this current work the detailed system design, prototypal implementation, operation, and laboratory characterization of the proposed $\mu \mathrm{GC}$ system, dubbed Zebra GC. Table 1-1 Summary and comparison of $\mu \mathrm{GC}$ systemsprovides a detailed comparison of four $\mu \mathrm{GC}$ systems, including Zebra GC, and highlights the features, advantages and disadvantages of different system components. As seen, other reported $\mu \mathrm{GC}$ systems [19-23], while producing promising results, use individually fabricated chips which lead to extra care to avoid compound condensation in cold spots. Also, some of these systems still use conventional components to achieve high performance which can lead to increased energy consumptions or increased analysis time. 
Table 1-1 Summary and comparison of $\boldsymbol{\mu G C}$ systems

\begin{tabular}{|c|c|c|c|c|}
\hline Features & $\begin{array}{l}\text { INTREPID system, } \\
\text { University of Michigan, } \\
\text { Ann Arbor [22] }\end{array}$ & $\begin{array}{l}\mu \mathrm{GC} \text { system, Arizona } \\
\text { State University [20] }\end{array}$ & $\begin{array}{l}\text { HGC system, CNR-IMM } \\
\text { Institute for } \\
\text { Microelectronics and } \\
\text { Microsystems [19] }\end{array}$ & $\begin{array}{l}\text { Zebra GC system, } \\
\text { Virginia Tech }\end{array}$ \\
\hline $\begin{array}{l}\text { Sampling } \\
\text { and } \\
\text { Injection }\end{array}$ & $\begin{array}{l}\text { Hybrid 2-stage (sorbent } \\
\text { tube + micro trap, } \\
\text { Carbopack) } \\
\text { Pros: Short sampling } \\
\text { time and sharp } \\
\text { injections } \\
\text { Cons: Power } \\
\text { consumption and trap } \\
\text { cleaning time increases. }\end{array}$ & $\begin{array}{l}\text { Sorbent tube packed } \\
\text { with Carbopack } \\
\text { Pros: High volume } \\
\text { sampled } \\
\text { Cons: High power } \\
\text { consumption, long } \\
\text { cleaning times and } \\
\text { wide injection plug }\end{array}$ & $\begin{array}{l}\text { Microfabricated cavity } \\
\text { packed with adsorbent. } \\
\text { Pros: Low power } \\
\text { consumption } \\
\text { Cons: Medium sample } \\
\text { volume and wide } \\
\text { injection plug }\end{array}$ & $\begin{array}{l}\text { Microfabricated } \\
\text { cavity with } \\
\text { embedded pillars and } \\
\text { TenaxTA coating } \\
\text { Pros: Low power } \\
\text { consumption, High } \\
\text { surface area, very } \\
\text { sharp injections } \\
\text { Cons: Low sample } \\
\text { volume }\end{array}$ \\
\hline Separation & $\begin{array}{l}\text { 1-m, spiral channel (150 } \\
\mu \mathrm{m} \times 240 \mu \mathrm{m} \text { ) PDMS } \\
\text { coated micro-column, } \\
\text { temperature controlled } \\
\text { Separation Time: } 1 \mathrm{~min}\end{array}$ & $\begin{array}{l}\text { Multiple } \\
\text { configurations. 2-m \& } \\
\text { 19-m carbowax } \\
\text { coated capillary } \\
\text { columns } \\
\text { Separation Time: } 3 \\
\text { min }\end{array}$ & $\begin{array}{l}0.5-\mathrm{m} \text {, spiral channel } \\
(800 \mu \mathrm{m} \text { deep) } \\
\text { carbograph packed } \\
\text { micro-column, } \\
\text { temperature controlled } \\
\text { Separation Time: } 10 \\
\text { min }\end{array}$ & $\begin{array}{l}\text { 2-m, rectangular } \\
\text { channel }(70 \mu \mathrm{m} \times 240 \\
\mu \mathrm{m}) \text { PDMS coated } \\
\text { micro-column, } \\
\text { temperature } \\
\text { controlled } \\
\text { Separation Time: } 1 \\
\text { min }\end{array}$ \\
\hline Detection & $\begin{array}{l}\text { Chemi-resistor array. } \\
\text { LODs }-0.48 \text { to } 2.2 \mathrm{ng} \text {. } \\
\text { Pros: Identification of } \\
\text { co-eluted compounds } \\
\text { Cons: Sensor response } \\
\text { varies with flow rate } \\
\text { and temperature, and } \\
\text { optimal operating point } \\
\text { changes according to } \\
\text { analyte }\end{array}$ & $\begin{array}{l}\text { Tuning-fork. } \\
\text { Sensitivity } 100 \text { ppbv. } \\
\text { Pros: Low power } \\
\text { consumption and high } \\
\text { selectivity } \\
\text { Cons: Long response } \\
\text { time }\end{array}$ & $\begin{array}{l}\text { Metal-oxide } \\
\text { semiconductor. } \\
\text { Sensitivity } 5 \text { ppbv } \\
\text { Pros: High sensitivity } \\
\text { Cons: Long-term drift, } \\
\text { Long response time }\end{array}$ & $\begin{array}{l}\mu T C D \text { embedded in } \\
\text { separation column. } \\
\text { LOD - } 1 \text { ng } \\
\text { Pros: High reliability, } \\
\text { Integrated, Low cost } \\
\text { Cons: Low selectivity }\end{array}$ \\
\hline $\begin{array}{l}\text { Integrated } \\
\text { System }\end{array}$ & $\begin{array}{l}\text { Carrier gas: Ambient-air } \\
\text { Pros: High } \\
\text { performance, selective, } \\
\text { fast analysis } \\
\text { Cons: High system } \\
\text { power consumption } \\
\text { expected due to } \\
\text { conventional trap }\end{array}$ & $\begin{array}{l}\text { Carrier gas: Ambient- } \\
\text { air } \\
\text { Pros: High selectivity } \\
\text { Cons: Only one } \\
\text { microfabricated } \\
\text { component, high } \\
\text { system power } \\
\text { consumption } \\
\text { expected }\end{array}$ & $\begin{array}{l}\text { Carrier gas: Ambient-air } \\
\text { Pros: All } \\
\text { microfabricated } \\
\text { components, Highly- } \\
\text { sensitive } \\
\text { Cons: Detector drifts } \\
\text { over time - } \\
\text { calibration(weekly) and } \\
\text { replacement (few } \\
\text { months) required }\end{array}$ & $\begin{array}{l}\text { Carrier gas: Helium } \\
\text { Pros: All } \\
\text { microfabricated } \\
\text { components, } \\
\text { monolithic } \\
\text { integration, good } \\
\text { performance, low } \\
\text { cost, high reliability } \\
\text { Cons: Low selectivity } \\
\text { detector, low sample } \\
\text { volumes }\end{array}$ \\
\hline
\end{tabular}




\subsection{Contributions}

The major contributions of this thesis are as follows:

1. A novel $\mu \mathrm{GC}$ architecture has been proposed which leverages monolithically integrated $\mu \mathrm{SC}$ and $\mu \mathrm{TCD}$. The architecture also includes a novel method to perform injections with a very sharp plug from the $\mu \mathrm{PC}$ even in the presence of flow-sensitive gas detectors like TCD.

2. A field-deployable $\mu \mathrm{GC}$ system is implemented through hybrid integration of microfabricated components, the flow controller unit, and all the necessary flow and thermal management as well as user interface circuitry.

3. Extensive laboratory characterization of the system has been performed for four VOCs identified as HAPs. A detailed comparison of the $\mu \mathrm{GC}$ system is reported against conventional ATD-GC-FID system for real gasoline samples in simulated field environment.

\subsection{Organization of Thesis}

The rest of this thesis is organized as follows:

Chapter 2 presents a brief background of conventional GC systems. We discuss the design and structure of contemporary $\mu \mathrm{GC}$ systems. An overview of the application of GC for environment monitoring is presented.

Chapter 3 presents the architecture and detailed-design of the proposed $\mu \mathrm{GC}$ system. Microfabricated components used in the system are described along with their fabrication process. Interface circuitry for microfabricated components and flow controllers is mentioned followed by system integration and operation cycles. 
Chapter 4 highlights the design iterations and components of Zebra GC. Details of the hardware, embedded software and application software implementations are provided.

Chapter 5 presents the laboratory characterization of system components followed by testing and characterization of integrated $\mu \mathrm{GC}$ system. A detailed comparison of the $\mu \mathrm{GC}$ system is reported against conventional ATD-GC-FID system for real gasoline samples in simulated field environment.

Chapter 6 concludes the thesis work. 


\section{Background and Motivation}

This chapter provides an overview of the design of conventional GC systems. Then, we discuss the design of $\mu \mathrm{GC}$ systems and micro-fabrication techniques deployed for such systems. Further, application of GC systems for environment monitoring is discussed.

\subsection{Conventional GC systems}

Gas chromatography is a technique used in analytical chemistry for separating chemicals in a complex mixture. The separation is based on partition equilibrium of analyte between a solid or viscous liquid stationary phase and a gas mobile phase. The mobile phase is mostly an inert gas whereas the stationary phase is a thin layer of liquid or polymer on the inner surface of a tube. As shown in Figure 2-1, GC systems are primarily comprised of an injector, a separation column and a detector. The injector provides a mechanism to inject analytes into the continuous stream of the carrier gas. For conventional GC systems, various mechanisms exist to achieve the same, examples of which are split/splitless injectors, gas switching valves, and purge-and-trap systems. Helium is the most commonly used carrier gas as it is non-flammable and is compatible with many detectors. The separation column is the primary component of the GC system and is responsible for separation of compounds in a complex mixture. Capillary columns are the most popular

choice in conventional systems owing to high separation efficiency. They are manufactured 
from fused silica tubing and are typically 10-50 meters long. A film of polymer stationary phase, typically less than $5 \mu \mathrm{m}$, is coated on the inner wall of the column. Once the analytes are introduced inside the column, the carrier gas sweeps them through the column. The motion of analytes is inhibited by the interaction with the stationary phase. The rate at which molecules progress depends on the strength of the interactions, which in turn depend on the type of molecule and stationary phase material. Since each type of molecule interact differently, their rate of progression varies and mixture gets separated by the time it reaches the end of the column [12].

The detectors measure the concentration of the gas stream at the outlet of column. Flame ionization detector (FID) and thermal conductivity detector (TCD) are examples of commonly used detectors in GC systems. A detector is characterized by the range of concentration and compounds it responds to. Both FID and TCD are sensitive to a wide range of compounds and concentrations. TCDs are more universal kind of detector and respond whenever the thermal conductivity of the analyte is different from that of the carrier gas. FIDs on the other hand are more sensitive than TCDs but they primarily respond to hydrocarbons. There are many other kinds of detectors which are more application specific including atomic emission detectors (AED) and flame photometric detectors (FPD).
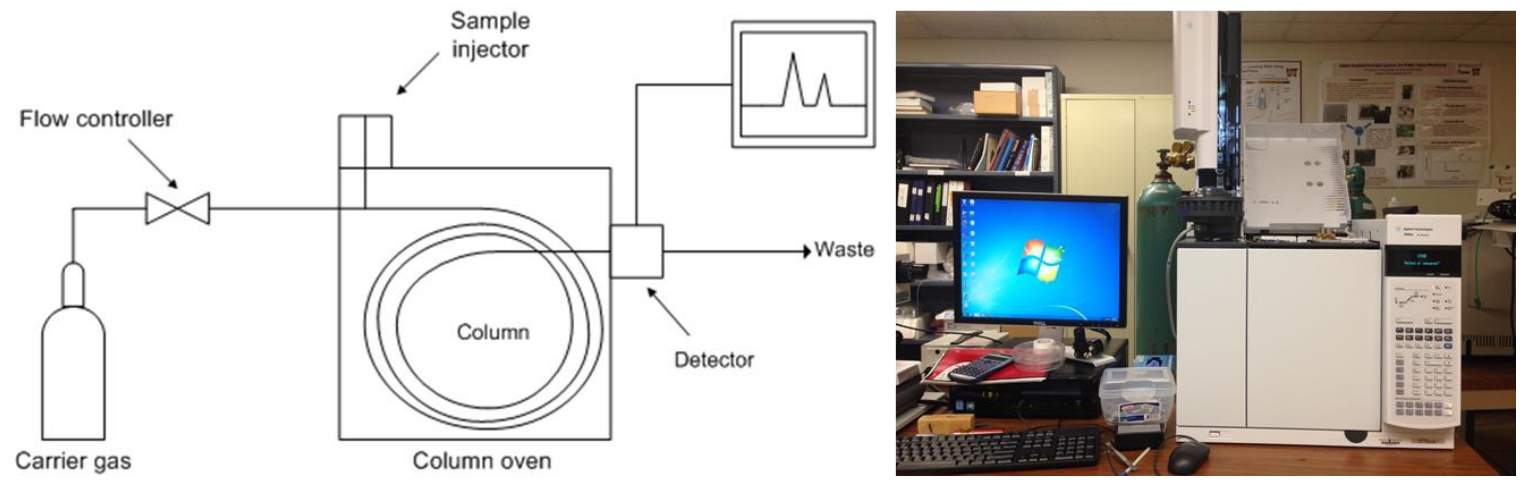

Figure 2-1 Schematic diagram and photograph of a GC system (Photo by Apoorva Garg, 2014) 
GC systems are typically used to test purity of a particular substance or separating compounds in a mixture to get relative amounts. Figure 2-2 shows the separation of a mixture of chemicals using a convention GC system. In some situations, GC may help in identifying a compound by measuring the retention time.

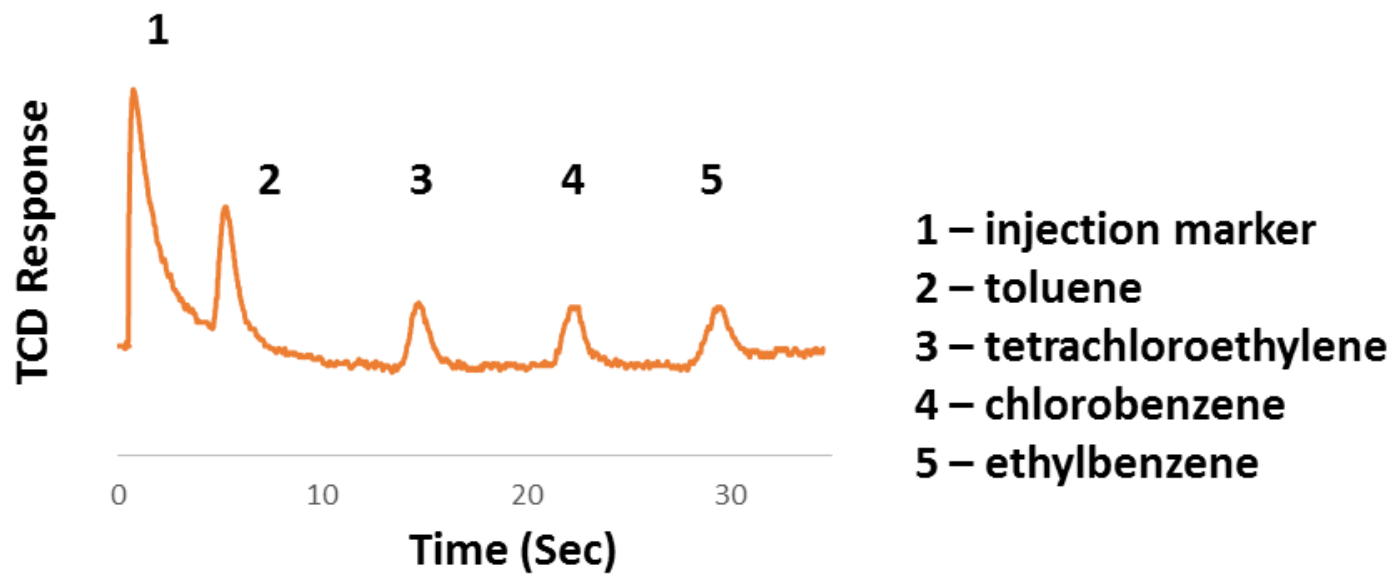

Figure 2-2 GC Analysis

\section{$2.2 \mu G C$ Systems}

Conventional GC systems are fairly bulky owing to the oven chamber and gas tanks. They also consume high power and have a slower response time due to the higher thermal intertia of the system. As these systems lack portability, their application is restricted to laboratory environments and analysis is done on samples collected from the field. With advances in microelectromechanical systems (MEMS) technologies, it has been possible to miniaturize different components of the GC System and integrate them to assemble a Micro Total Analysis System ( $\mu$ TAS). Figure 2-3 shows the schematic of one such system. 


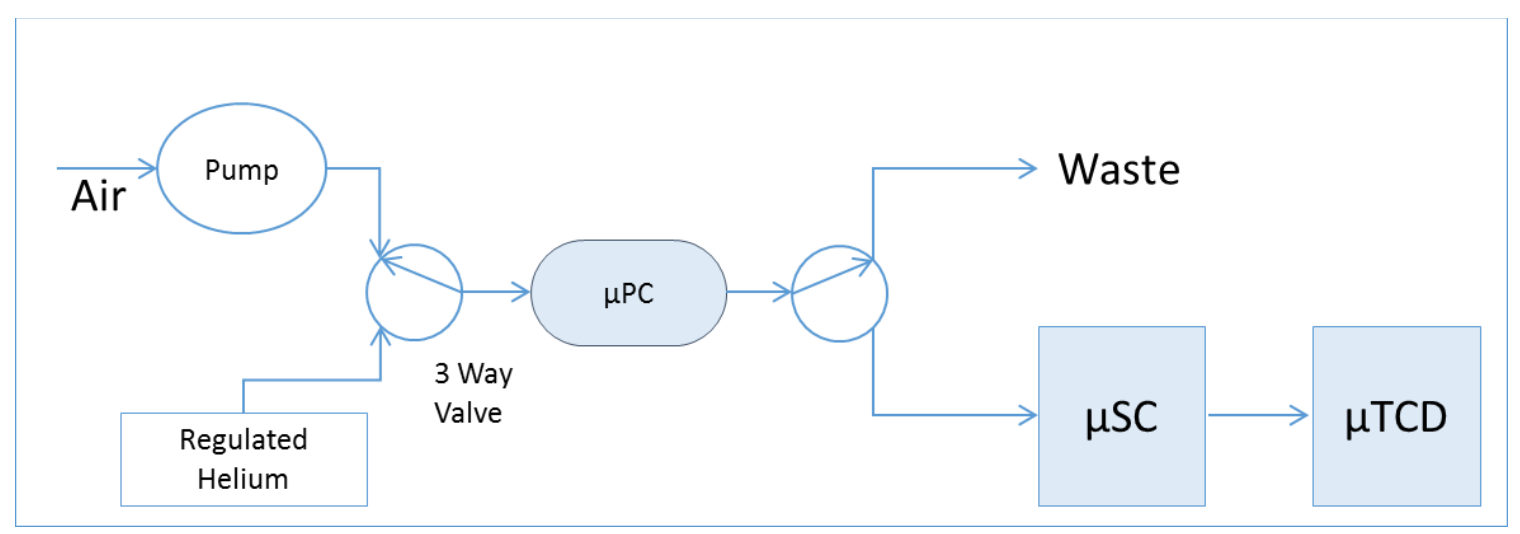

Figure 2-3 Schematic diagram of $\mu \mathrm{GC}$ system

$\mu \mathrm{GC}$ systems typically consist of three main micro-fabricated components: preconcentrator/injector, separation column, and detector. Current generation of $\mu \mathrm{GCs}$ are realized via hybrid integration of micro-fabricated chips, flow controller and control and measurement circuitry. Few systems which are completely based on micro-fabricated components have been reported [24]. Although such systems have advantages in terms of compact design and lower power consumption, they suffer from performance loss due to limited capabilities and complexities of using contemporary micro-fabricated pumps and valves. Following section elaborates on technologies used for various components of $\mu \mathrm{GC}$ systems.

\subsubsection{Injector}

Sample loops and preconcentrators are the most popular injection method for $\mu \mathrm{GC}$ systems. Sample loops are essentially micro-machined channels in silicon with volumes typically ranging from 1-10 $\mu \mathrm{L}$. Preconcentrators are better suited for vapor phase analysis and both, conventional thermally desorbed preconcentrators (TPCs) and $\mu$ PCs, are used in current generation of $\mu \mathrm{GC}$ systems. The conventional ones consist of short-length mircobore tubing packed with an absorbent which is heated through a wire wrapped around the tube for desorption. $\mu \mathrm{PCs}$, on the other hand, have novel configurations including packed compartments, coated planar surface, and micro-3D structures. $\mu$ PCs have advantages like smaller size, lower pressure drop, lower power consumption and higher efficiencies but they have drawbacks in terms of limited sample capacity and lower 
breakthrough volume. This problem is overcome by increasing the surface area to volume ratio by utilizing novel geometries like embedded pillars.

\subsubsection{Separation Column}

Microfabricated separation columns are heart of the $\mu \mathrm{GC}$ systems as they physically separate a mixture into separate compounds. These columns are fabricated by etching highaspect-ratio rectangular channels in silicon and laid out in circular or square-spiral configurations [11]. Pyrex substrate is used to seal the channels through anodic bonding. The inner walls of column are coated by a stationary phase, like polydimethylsiloxane (PDMS), to separate analytes based on their interaction with such phases. Thin film heaters and sensors are also deposited on the backside of $\mu \mathrm{SCs}$ for temperature programming. $\mu \mathrm{SCs}$ have advantages like faster analysis time, lower power consumption and compact design, making them suitable for portable $\mu \mathrm{GC}$ systems. As compared to conventional columns, they suffer from lower peak capacity, which can be resolved to some extent with novel architectures like semi-packed [12] and multi-capillary columns [13].

\subsubsection{Detectors}

Miniaturized gas detectors have been an area of active research from many years. There have been efforts to develop miniaturize gas detectors based on plethora of technologies like thermal conductivity detectors (TCD), flame ionization detectors (FID), photo ionization detectors (PID), surface acoustic wave (SAW) resonators, and chemiresistor arrays. $\mu \mathrm{TCD}$ and $\mu \mathrm{PID}$ are relatively more popular in current generation of industrial $\mu \mathrm{GC}$ systems. Sensitivity, selectivity and power consumptions are the most important criterion for selecting the detector for $\mu \mathrm{GCs}$.

\subsubsection{Flow Control}

Gas flow in $\mu \mathrm{GCs}$ is manipulated using conventional mini pumps and valves. The microfabricated counterparts often suffer from drawbacks like lower performance, complex control scheme and low reliability. Micro-fabricated pumps and valves are an active area of research as they have wide range of applications and will play a crucial role in monolithic integration of $\mu \mathrm{GC}$ systems. 


\subsection{Application of GC for environment monitoring}

Gas chromatography coupled with flame ionization detector (GC-FID) is a popular analytical technique for monitoring VOCs in environment samples [25]. Although GC-FID systems are highly reliable and accurate, they are expensive, bulky, power hungry and often require a trained technician. Laboratory and sample collection site are mostly at different locations, therefore the sample is collected using sorbent tubes, canisters or tedlar bags. Due to manual intervention during sample collection, storage and transportation, there are high chances of sample contamination and loss.

Portable $\mu \mathrm{GC}$ systems provide a comprehensive solution and address most of the problems faced by conventional systems. Such systems leverage micro-fabrication techniques to achieve small form factor, lower power consumption and faster analysis time leading to near real-time detection of VOCs in environment samples. 


\section{Zebra GC System Architecture, Design and Operation}

This chapter discusses the design and architecture of the proposed $\mu \mathrm{GC}$ system, named Zebra GC system. $\mu \mathrm{GC}$ platforms typically consist of a preconcentration, a separation, and a detection unit. Zebra GC system is an effort towards monolithic integration by embedding the detector inside the separation column.

The system is comprised of microfabricated components which are integrated with off-theshelf flow controllers to implement GC flow cycles. An embedded platform, based on an 8-bit microcontroller, is responsible for fluidic and thermal control. It also implements the user interface, signal processing and data communication circuitry. The system is highly portable, battery powered and easy to operate. It can operate in a stand-alone mode or can be paired with a laptop for device control and data visualization through a Labview application. This chapter also details the integration and operation aspects of the system.

\subsection{Microfabricated Components}

The system deploys two MEMS components, $\mu \mathrm{PC}$ and $\mu \mathrm{SC}$ embedded with $\mu \mathrm{TCD}(\mu \mathrm{SC}$ TCD). These components have been previously developed by our research group [18, 26- 
30] and the following sections briefly describe the fabrication process, schematically shown in Figure 3-1.

Silicon wafers ( 4 inch diameter, $500 \mu \mathrm{m}$ thick, $\mathrm{n}$-type, double side polished) and Borofloat wafers (4 inch diameter, $700 \mu \mathrm{m}$ thick, double side polished) were purchased from University wafers and Coresix Precision Glass (Williamsburg, VA), respectively. Tenax TA (80/100 mesh) and all other chemicals used for chromatographic testing were of analytical standard (>99\% purity) and purchased from Sigma-Aldrich (St. Louis, MO). AZ 9260 photoresist and polydimethysiloxane (OV-1) were purchased from MicroChemicals (Germany) and Ohio Valley (Marietta, OH), respectively. Fused capillary tubes (200 $\mu \mathrm{m}$ outer diameter, $100 \mu \mathrm{m}$ inner diameter,) were purchased from Polymicro Technologies (Phoenix, AZ).

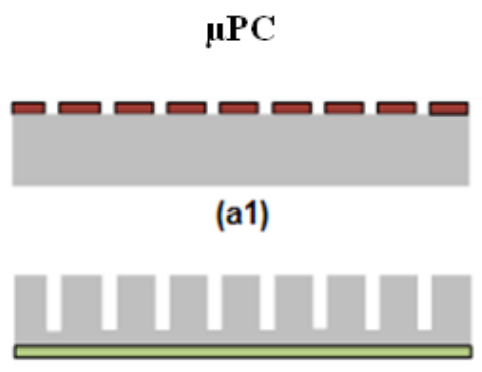

(a2)

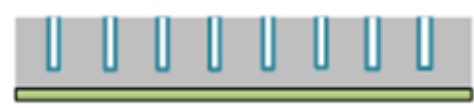

(a3)

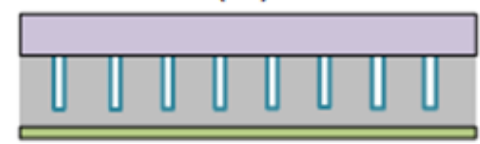

(a4)

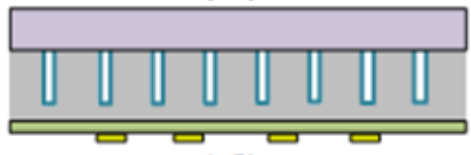

(a5)

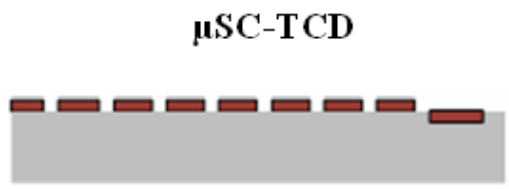

(b1)

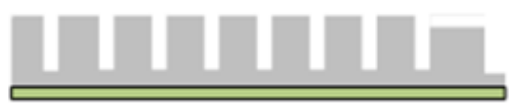

(b2)

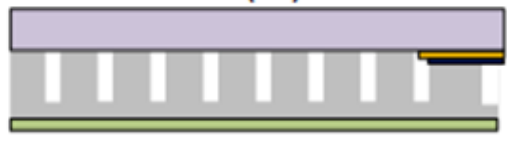

(b3)

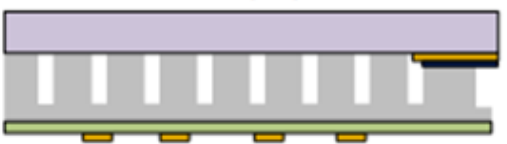

(b4)

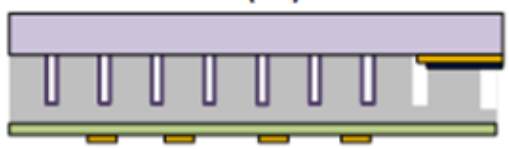

(b5)

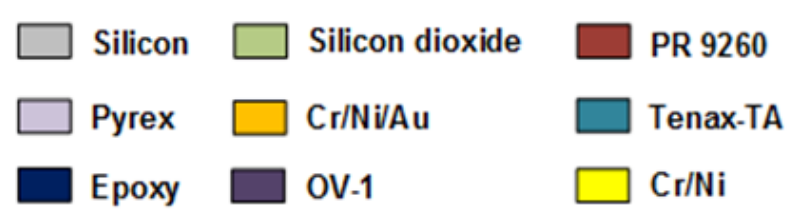

Figure 3-1: Process flow for the fabrication of $\mu \mathrm{PC}$ and $\mu \mathrm{SC}$-TCD 


\subsection{1 $\mu$ PC chip}

The fabrication of $\mu \mathrm{PC}$ was performed on a standard 4" wafer using MEMS processing technology. First, photolithography was performed to pattern micro-posts/fluidic ports using AZ9260 photoresist (Figure 3-1-a1). The wafer was then subjected to deep reactive ion etching (DRIE, Alcatel) to achieve a depth of $\sim 240 \mu \mathrm{m}$. After stripping the photoresist off the front-side, a 1- $\mu \mathrm{m}$ thick oxide layer that acts as an insulator was deposited on the backside. (Figure 3-1-a2). The wafer was then diced into individual chips. The chip was then filled with Tenax TA solution (10 mg/mL in dichloromethane). After evaporation of the solvent, a thin film ( $200 \mathrm{~nm}$ ) of the polymer adsorbent remained on the cavity surfaces (Figure 3-1-a3). The chip was then capped with a Borofloat wafer by anodic bonding (Figure 3-1-a4). Following bonding, the chips were loaded onto the plate of an e-beam evaporator (PVD-250, Kurt Lesker) with the backside facing the crucible. The chips were masked by a stainless steel shadow mask patterned with the features defining the heater and sensor. Following this, $40 \mathrm{~nm} / 230 \mathrm{~nm}$ of $\mathrm{Cr} / \mathrm{Ni}$ was deposited to get nominal resistances of $15 \Omega$ and $250 \Omega$ for the heater and sensor, respectively (Figure 3-1-a5). Finally, fused capillary tubes were inserted and epoxied to the inlet/outlet ports. Optical and SEM images of the chip are shown in Figure 3-2.

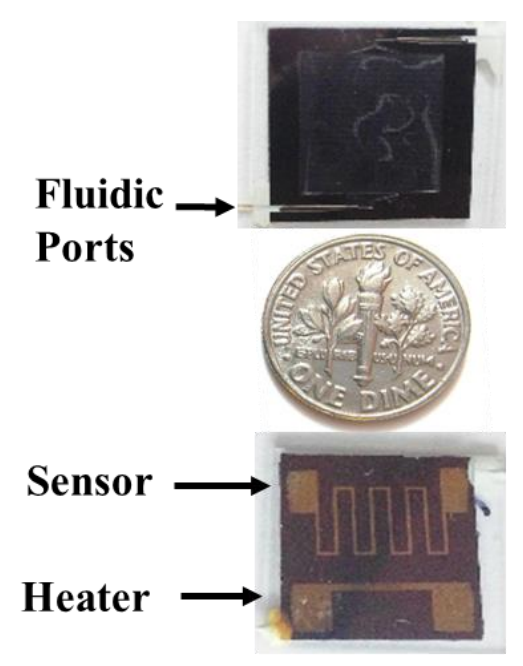

a) Optical image of front (top) and back (bottom) side of $\mu \mathrm{PC}$ chip

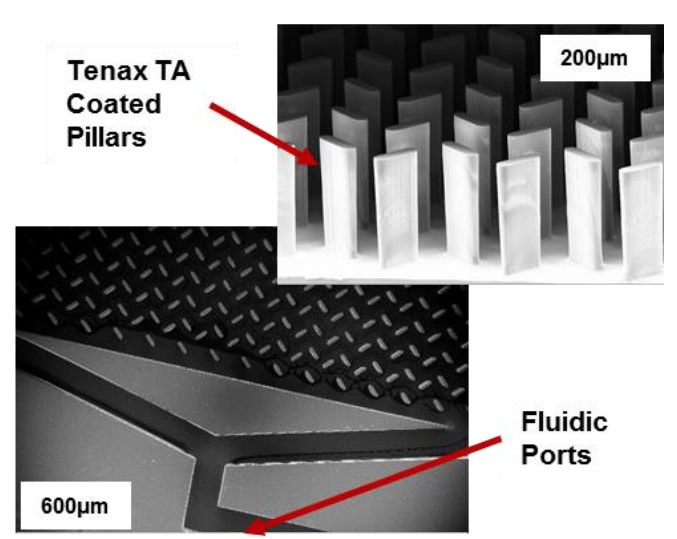

b) SEM image of embedded pillars and Tenax coating

Figure 3-2 Images of $\mu \mathrm{PC}$ chip 


\subsection{2 $\mu S C-T C D$}

A two-step anisotropic etching of silicon was performed for hosting the feedthroughs and microfluidic channel. The wafer was spin coated with S1813 to create a shallow depth of 2-3 $\mu \mathrm{m}$ (Figure 3-1-b1). This shallow depth prevents contact between the metal interconnects on the Borofloat wafer and the walls of the separation column in silicon upon bonding. After stripping the photoresist, DRIE was used to create $240-\mu \mathrm{m}$-deep channels with the desired dimensions using AZ9260 as the photoresist. After stripping the photoresist off the front-side, a $1 \mu \mathrm{m}$ thick oxide layer that act as an insulator was deposited on the backside. (Figure 3-1-b2). Afterwards, TCD resistors were fabricated on a glass substrate by utilizing a lift-off process of a $40 \mathrm{~nm} / 100 \mathrm{~nm} / 25 \mathrm{~nm} \mathrm{Cr} / \mathrm{Ni} / \mathrm{Au}$ stack in the ebeam evaporator. The diced detector on glass and the diced separation column on silicon were then aligned and anodically bonded together (Figure 3-1-b3). A $40 \mathrm{~nm} / 100 \mathrm{~nm} / 25 \mathrm{~nm}$ of $\mathrm{Cr} / \mathrm{Ni} / \mathrm{Au}$ stack was evaporated on backside of the chip to serve as heaters and temperature sensors using stainless steel shadow mask (Figure 3-1-b4). Afterwards, the capillary tubes were epoxied into the inlet/outlet ports. The chip was statically coated with dimethyl-polysiloxane (OV-1) by filling it with a solution of $10 \mathrm{mg} / \mathrm{mL} \mathrm{OV-1}$ in pentane, followed by carefully sealing one end with wax and pulling a vacuum at the open end. This left a thin layer of OV-1 coating $(\sim 250 \mathrm{~nm})$ on the walls of the column channel (Figure 3-1-b5). An SEM image of the OV-1 coating and optical image of the chip is shown in Figure 3-3. 

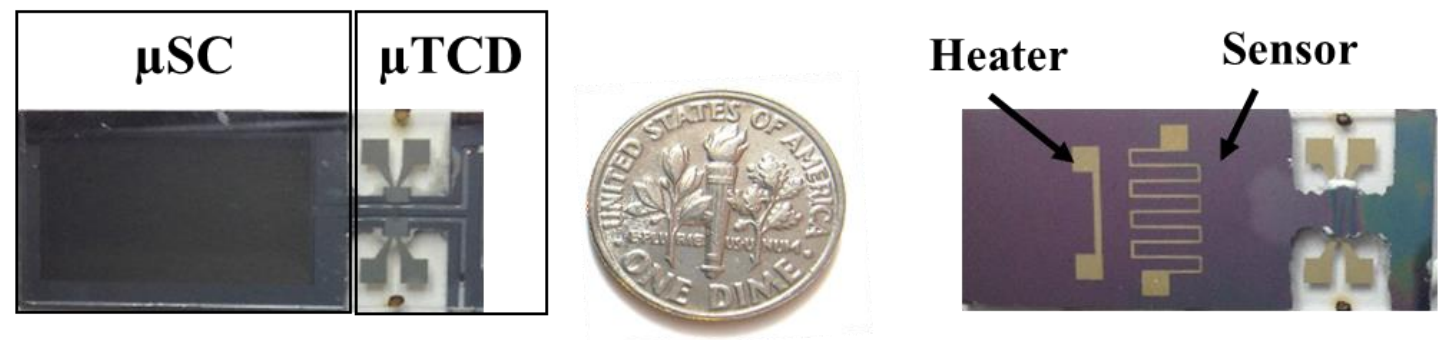

a) Optical image of front (left) and back (right) of $\mu$ SC-TCD chip
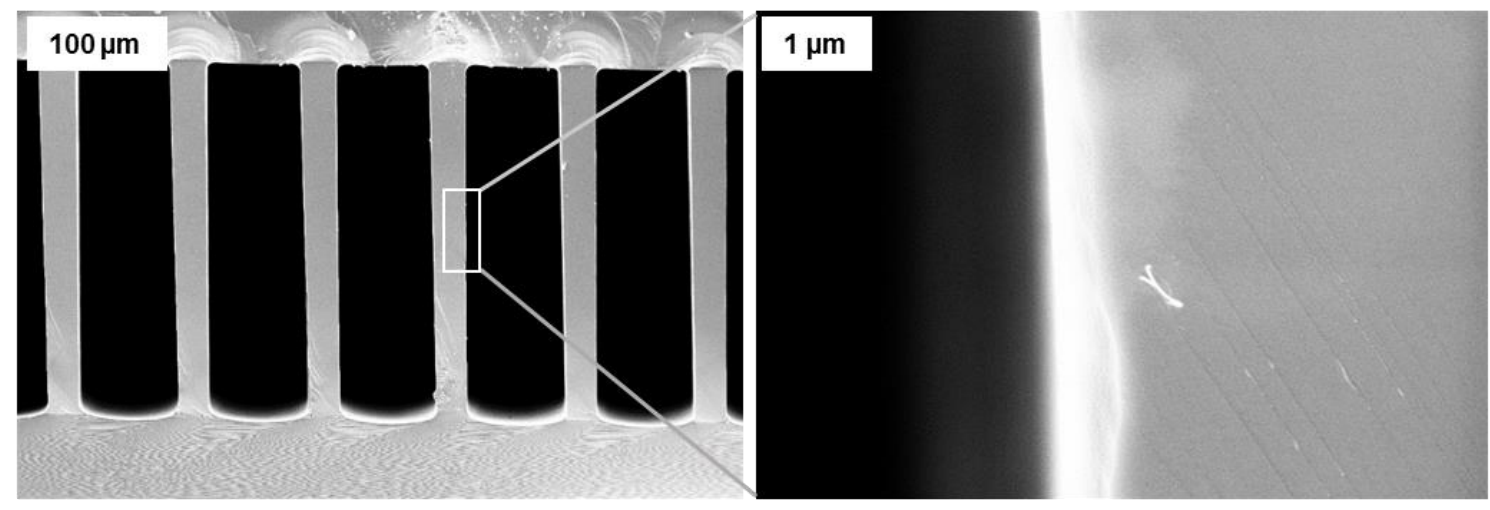

b) SEM images of PDMS coating on the interior wall of the column channel

Figure 3-3 Images of $\mu \mathrm{SC}-\mathrm{TCD}$ chip

\subsection{Integrated electronic module}

The microfabricated components integrated with the pump, multi-way valves and a portable helium cylinder; are controlled through an integrated electronic module which is managed by an 8-bit micro-controller. The block diagram of the integrated electronic module is shown in Figure 3-4 and the sub-modules are described in the following sections. 


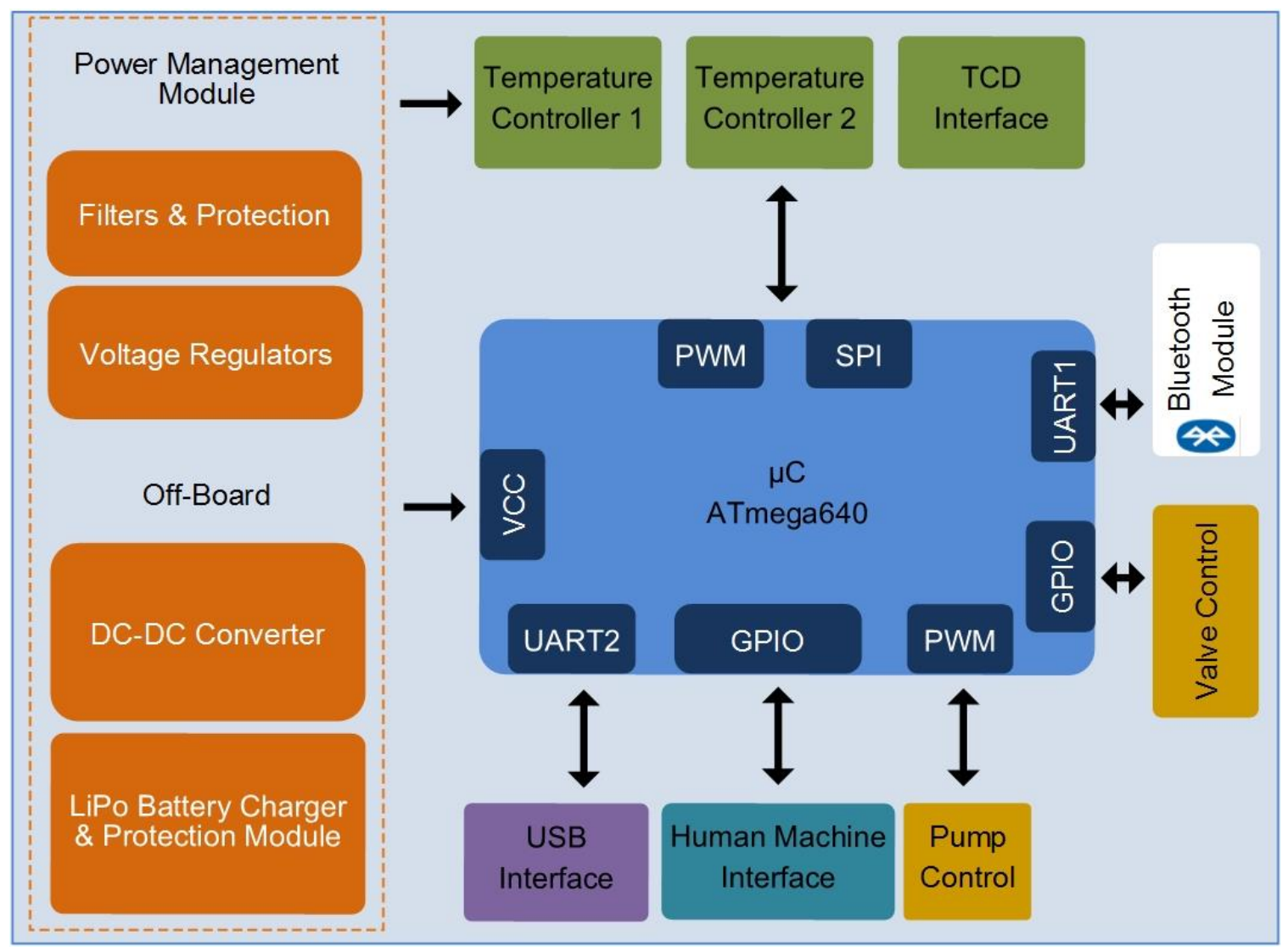

Figure 3-4 Integrated Electronic Module

\subsubsection{Valve control}

Multi-way valves are needed to manipulate gas flow in microfabricated chips to implement GC cycles: loading, injection, analysis, and cleaning. Miniature 3-way latching solenoid valves (LHLA0521111H, The Lee Co.) were selected to optimize power consumption. These valves provide very low fluidic resistance and have extremely low leakage rates. The valves are interfaced to MEMS chips and other flow controllers through a custom designed PEEK manifold manufactured by Valco Instruments Co. As shown in Figure 3-5, the valves are driven by an H-bridge IC (L298, STMicroelectronics) which is controlled by the micro-controller. The valve is switched by applying a 5V DC pulse for $100 \mathrm{~ms}$ and polarity of the pulse controls valve's position. Freewheeling diodes eliminate chances of fly-back due to inductive characteristic of valve's electrical load. 

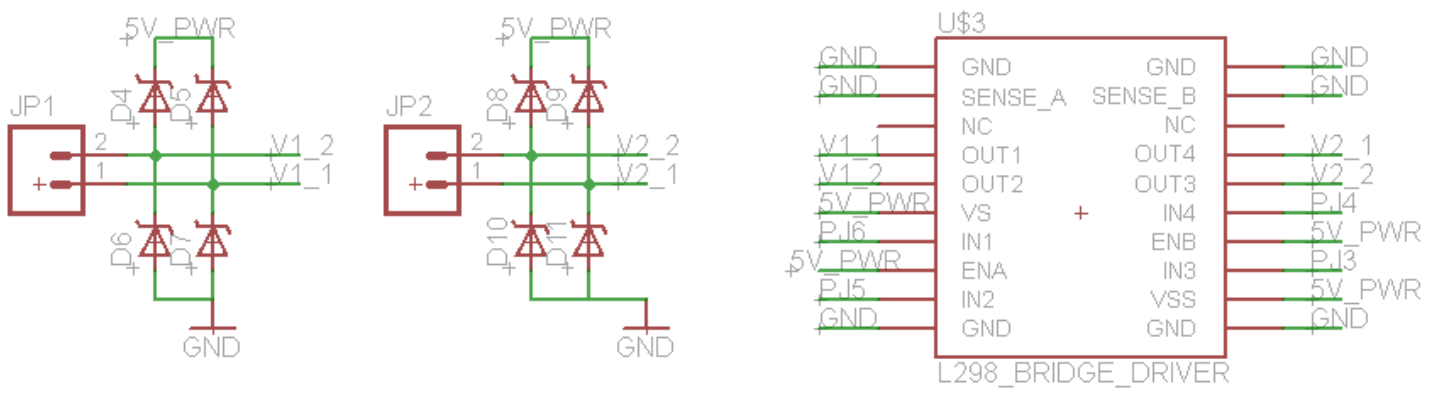

Figure 3-5 Valve Control Circuit Diagram

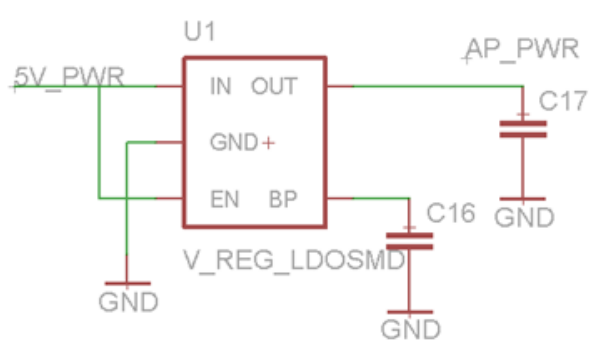

a) Power supply

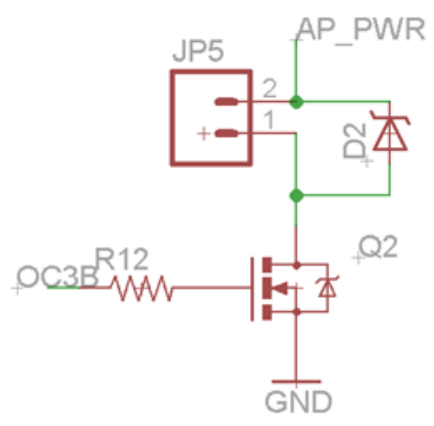

a) Control interface

Figure 3-6 Pump Control Circuit Diagram

\subsubsection{Pump control}

Pump is required to load environment sample into the $\mu \mathrm{PC}$ during loading stage. Miniature diaphragm pump (T2-05, Parker Hannifin) was selected to ensure compact design and low power consumption. As shown in Figure 3-6, the pump is controlled by an N-Channel MOSFET which is driven by pulse-width modulation (PWM) channel of micro-controller. $\mu$ PC's loading flow rate is adjusted by varying the pulse-width modulation (PWM) duty cycle, which is an important parameter during sample collection. 


\subsubsection{Temperature controller}

On-chip temperature sensors are connected in a 3-wire resistance temperature detector (RTD) configuration. The 3-wire configuration utilizes two well-matched current sources on the 24-bit ADC (AD7793, Analog Devices) and mitigates the effect of lead resistance on the sensor output. The reference voltage for the ADC is also generated using these matched current sources, through a precision resistor connected to the differential reference pins of the ADC. This scheme ensures that the span of the analog input voltage remains ratio-metric to the reference voltage and any error in the former due to temperature drift of the excitation current is compensated by the variation of the latter. The ADC is interfaced to the micro-controller through serial peripheral interface (SPI) bus, schematically shown in Figure 3-7.

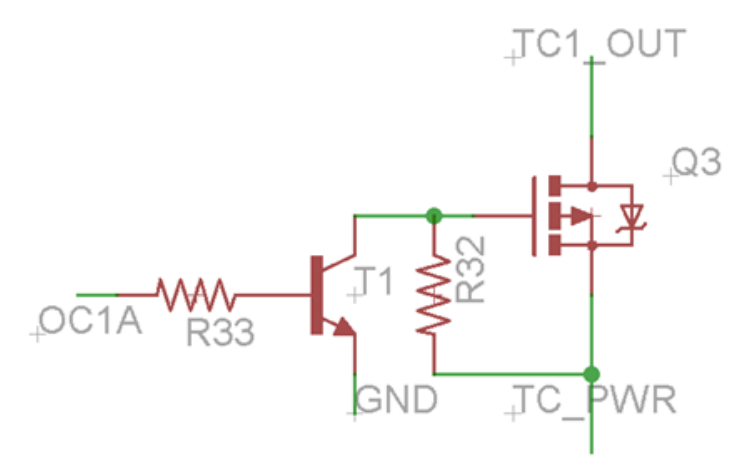

a) Heater interface

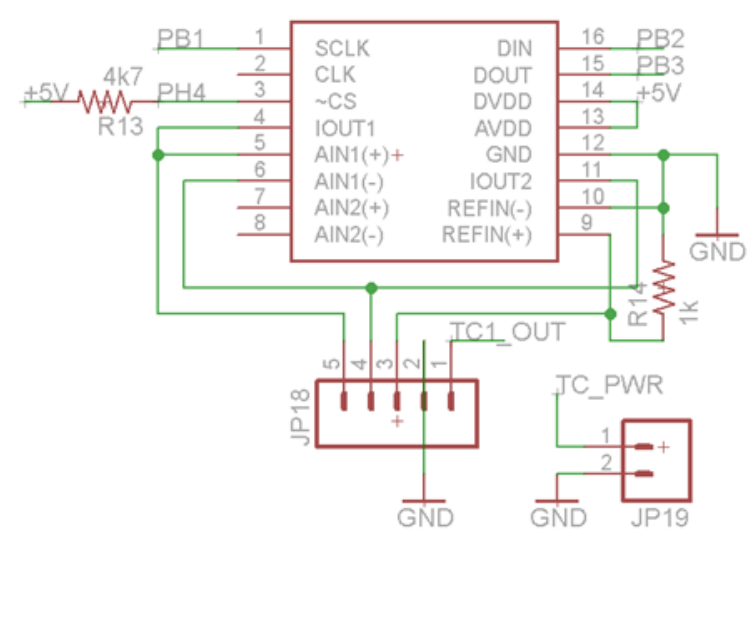

a) Temperature Sensor Interface

Figure 3-7 Temperature Controller Circuit Diagram

On-chip heaters are connected to a P-Channel MOSFEL and are controlled through PWM channels of the micro-controller. A closed loop digital proportional control system is implemented as part of the embedded firmware, which generates different profiles for temperature reference signal based on user input (initial temperature, step, ramp, final temperature). 


\subsection{4 $\mu$ TCD Interface}

The $\mu$ TCD is connected in a Wheatstone- bridge configuration, and the bridge is driven from an adjustable linear voltage regulator as shown in Figure 3-8. The differential signal from the bridge is fed into an ultra-low noise 24bit ADC (AD7793, Analog Devices) and is amplified using the on-chip programmable gain amplifier (PGA). The signal is filtered digitally, using an on-chip low pass modified Sinc3 filter that also provides $60 \mathrm{~Hz}$ rejection. The $\mu \mathrm{TCD}$, along with the entire system, is operated at a data rate of $10 \mathrm{~Hz}$, which provides substantial resolution for the peaks.

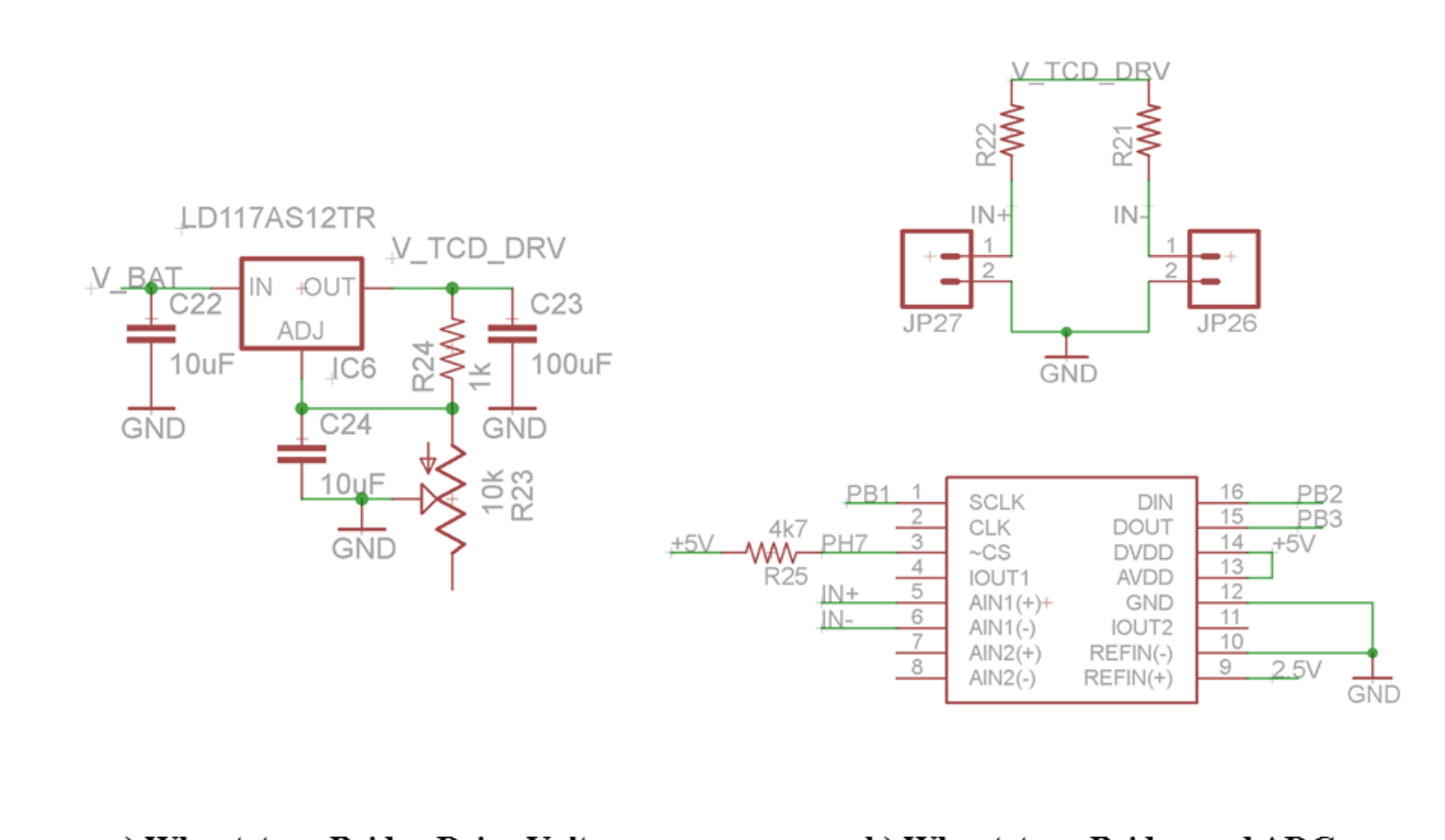

a) Wheatstone Bridge Drive Voltage

b) Wheatstone Bridge and ADC

Figure 3-8 $\mu$ TCD Interface Circuit Diagram

\subsubsection{Human Machine Interface and Data Acquisition}

Zebra GC can be operated in standalone mode using the LCD/Keypad based humanmachine interface, which has a menu driven system. The user can operate the system either in manual or automatic mode. In manual mode, the user can control each fluidic component and set important system parameters like flow rate, heating ramp rate, loading time, and analysis time. In automatic mode, the user can choose from some pre-defined automated 
cycles, like loading and injection, and also, run a complete fully-automated measurement cycle. Once the mode is selected, the screen shows the state of the system in terms of valve positions, temperature readings, pump duty cycle, and sensor value.

The system can be tethered to a Windows-based laptop through a USB or Bluetooth interface. A USB UART interface IC (FT232R, FTDI Ltd.) is used for wired data acquisition as shown in Figure 3-9. The wireless interface is implemented through a Bluetooth stack encapsulated module (RN-41, Roving Networks) connected to UART port of the micro-controller. A Labview application has been developed for controlling the device, visualizing and recording the data.

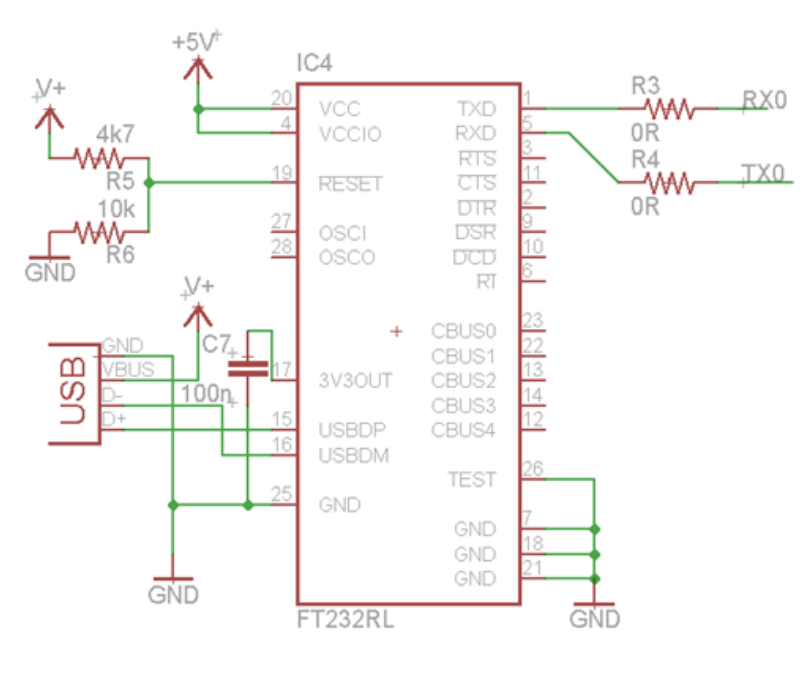

a) USB Interface
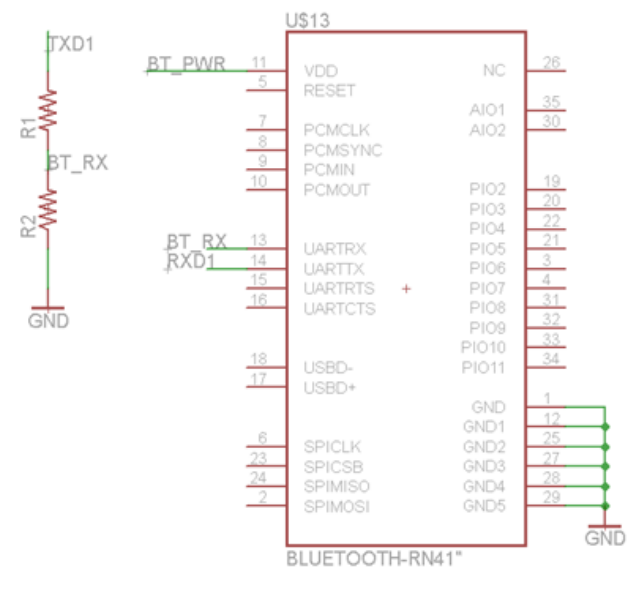

b) Bluetooth Interface

Figure 3-9 Data Acquisition Interface Circuit Diagram

\subsection{System Integration and Operation}

All microfabricated components along with the flow controllers, fluidic interfaces, electronics module, and user interface circuitry were assembled inside an Abs plastic box 
as schematically shown in Figure 3-10. The box also houses a lithium ion battery pack and a small helium cylinder to make the system highly portable.

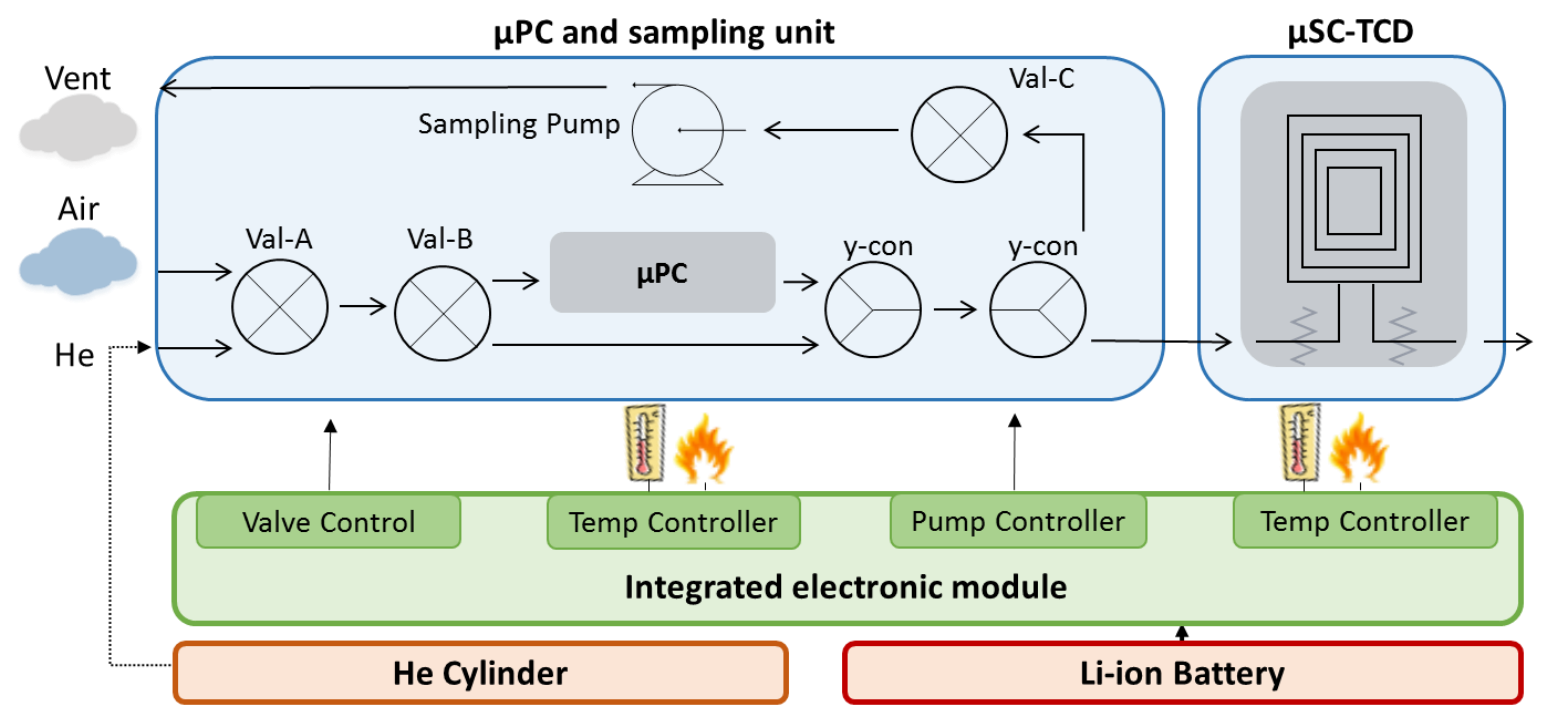

Figure 3-10 Zebra GC Schematic Diagram

Zebra GC has the following automated modes programmed in the system: 1) Loading, 2) Injection, 3) Analysis, and 4) Cleaning. Figure 3-11 shows the timing diagram in terms of valve positions and chip temperatures for different stages of operation, which are elaborated in the following sections. 


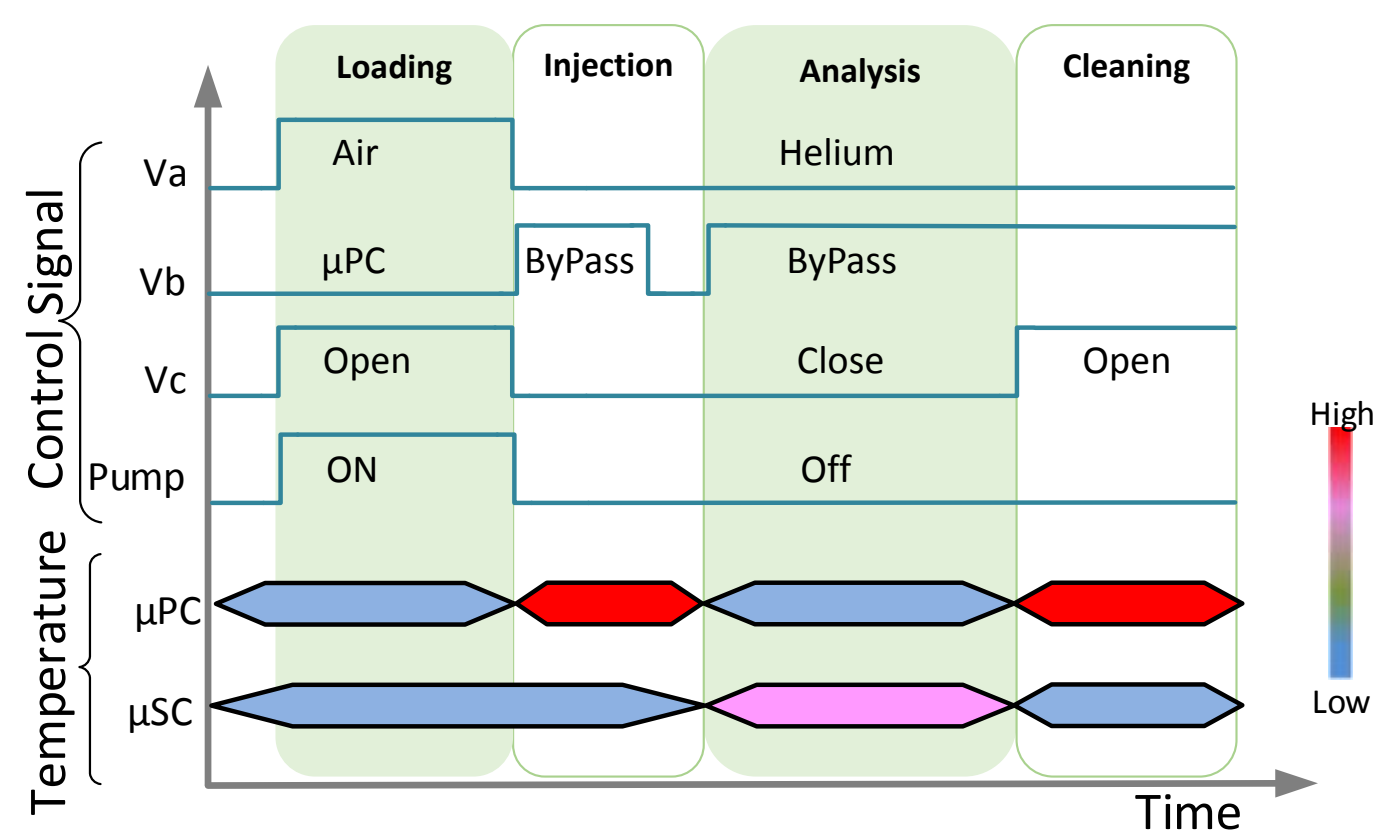

Figure 3-11 Timing Diagram

\subsubsection{Loading}

The pump applies negative pressure at the outlet of $\mu \mathrm{PC}$ to load it with VOCs present in the air sample. The optimal loading flow rate, set to $1 \mathrm{~mL} / \mathrm{min}$, depends on the design of $\mu \mathrm{PC}$, the adsorption efficiency and the breakthrough volume. The user can adjust the loading time, with longer duration resulting in an increase in sensitivity ( $\sim 50 \mathrm{ppbv})$. Figure 3-12 shows the flow path during loading stage.

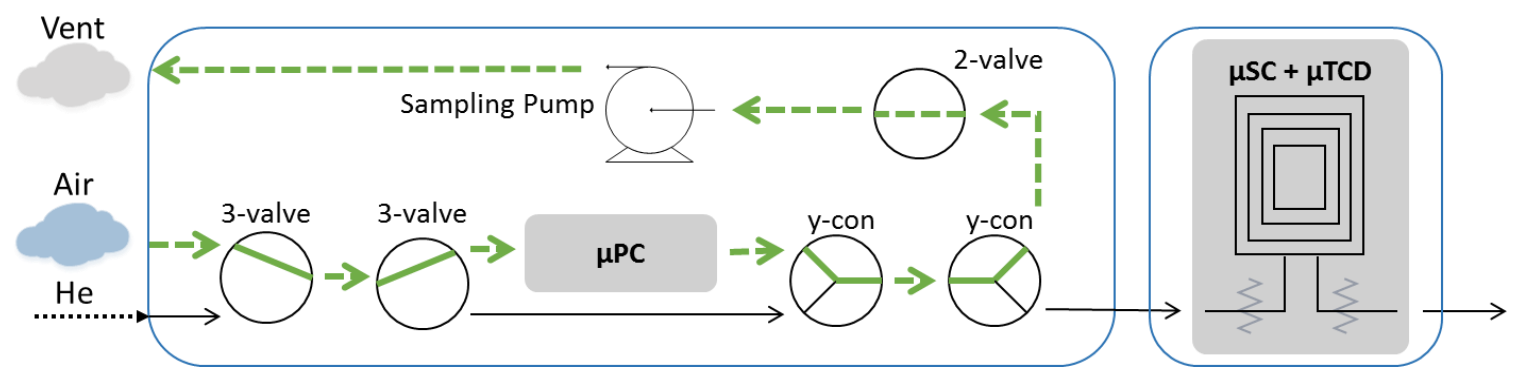

Figure 3-12 Loading Stage Flow Diagram 


\subsubsection{Injection}

As shown in Figure 3-13, the injection cycle is a 2-step process. Once sufficient sample is loaded into the $\mu \mathrm{PC}$, the valves are switched to flow helium through the bypass path into the $\mu \mathrm{SC} . \mu \mathrm{TCD}$ is allowed to stabilize for desorption flow. Desorption peak width from the $\mu \mathrm{PC}$ depends on the vapor desorption rate and transport time. In order to ensure sharp injection plug, the $\mu \mathrm{PC}$ is heated first at $25{ }^{\circ} \mathrm{C} / \mathrm{s}$ to $200{ }^{\circ} \mathrm{C}$ without flow, and then a valve is switched to inject analytes into the $\mu \mathrm{SC}$. The proposed 2-step injection scheme mitigates the effect of vapor desorption time on desorption peak width. This stage typically lasts 10$12 \mathrm{~s}$.

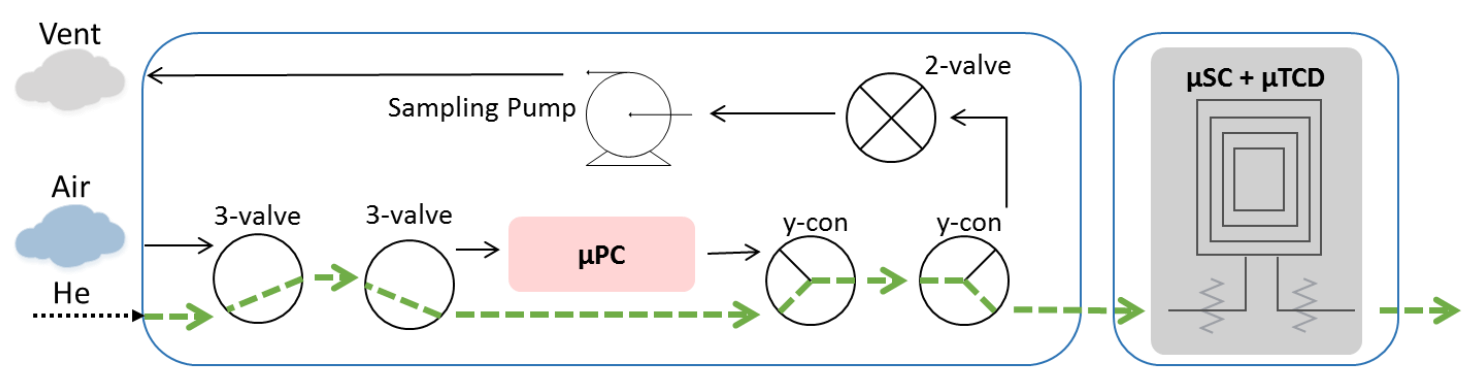

a) Step 1

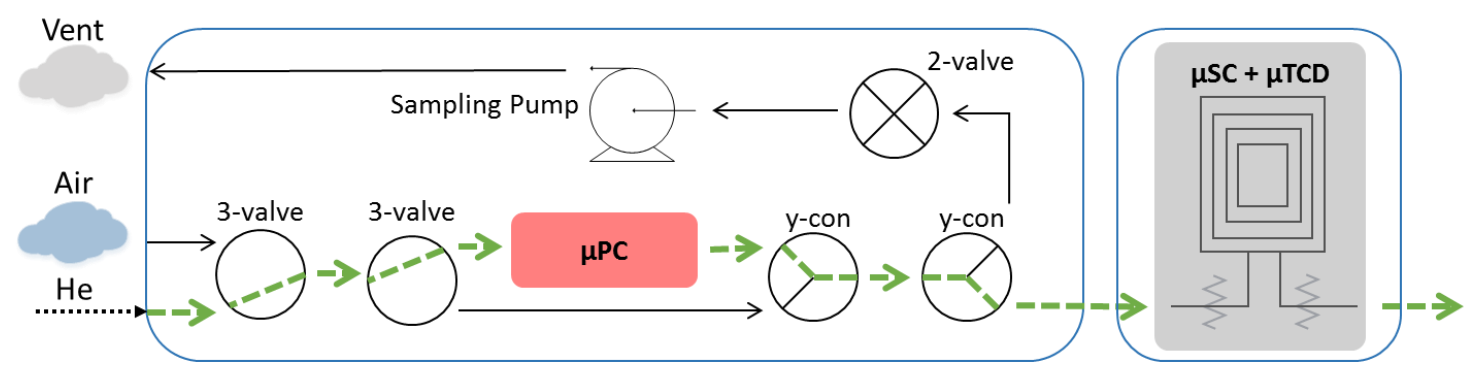

b) Step 2

Figure 3-13 Injection Stage Flow Diagram

\subsubsection{Analysis}

Once the analytes are injected in the $\mu \mathrm{SC}$, the valve is switched to bypass the $\mu \mathrm{PC}$. The analytes get separated in the $\mu \mathrm{SC}$ based on their different interactions with the stationary phase. The $\mu$ TCD responds to differences in thermal conductivity of the analytes and the carrier gas, and therefore detects the peaks as they elute from the $\mu \mathrm{SC}$. This phase typically 
lasts 1-2 min. $\mu \mathrm{SC}$ can function at higher temperatures to reduce analysis time or avoid condensation of high-boilers if needed. The $\mu \mathrm{SC}$ may require cleaning after few cycles and can be temperature cycled at higher temperatures for the same.

\subsubsection{Cleaning}

Once the analysis phase is complete, the valves are switched back to flow helium at 3 $\mathrm{mL} / \mathrm{min}$ through the $\mu \mathrm{PC}$ as show in Figure 3-14. The $\mu \mathrm{PC}$ is heated several times if necessary, to minimize residual analytes from the previous run. Typically, one temperature cycle is sufficient to desorb the remaining analytes because of the high desorption efficiency of the $\mu \mathrm{PC}$. Also, due to low thermal mass of $\mu \mathrm{PC}$, it cools down much faster as compared to conventional traps. This process takes around 10-12 s.

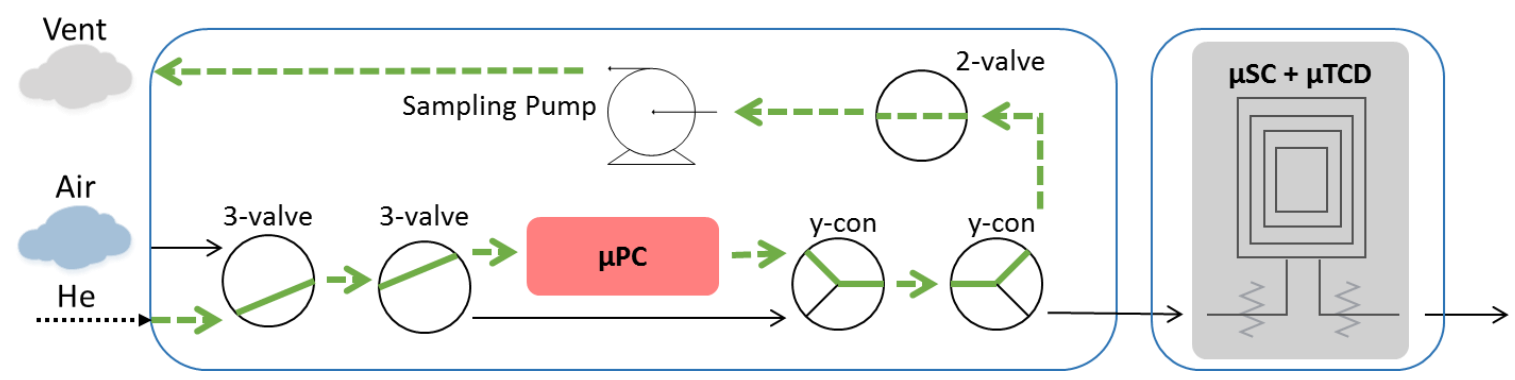

Figure 3-14 Cleaning Stage Flow Diagram 


\section{Zebra GC System Implementation}

A field-ready prototype of Zebra GC system was developed by fabricating and integrating various sub-modules. This chapter reports the design iterations and the final prototypal implementation.

\subsection{Early prototypes}

The first prototype (Figure 4-1) was developed by interfacing custom designed modules with an Arduino UNO board. A LCD/keypad shield for arduino was used to implement the user interface. The modules for temperature control, valve control and pump control were fabricated on general purpose PCB boards. All modules were tested and revised separately, followed by integration. The setup was mounted inside the benchtop GC oven and FID was used as the gas detector to test the working of $\mu \mathrm{PC}$ and $\mu \mathrm{SC}$. 


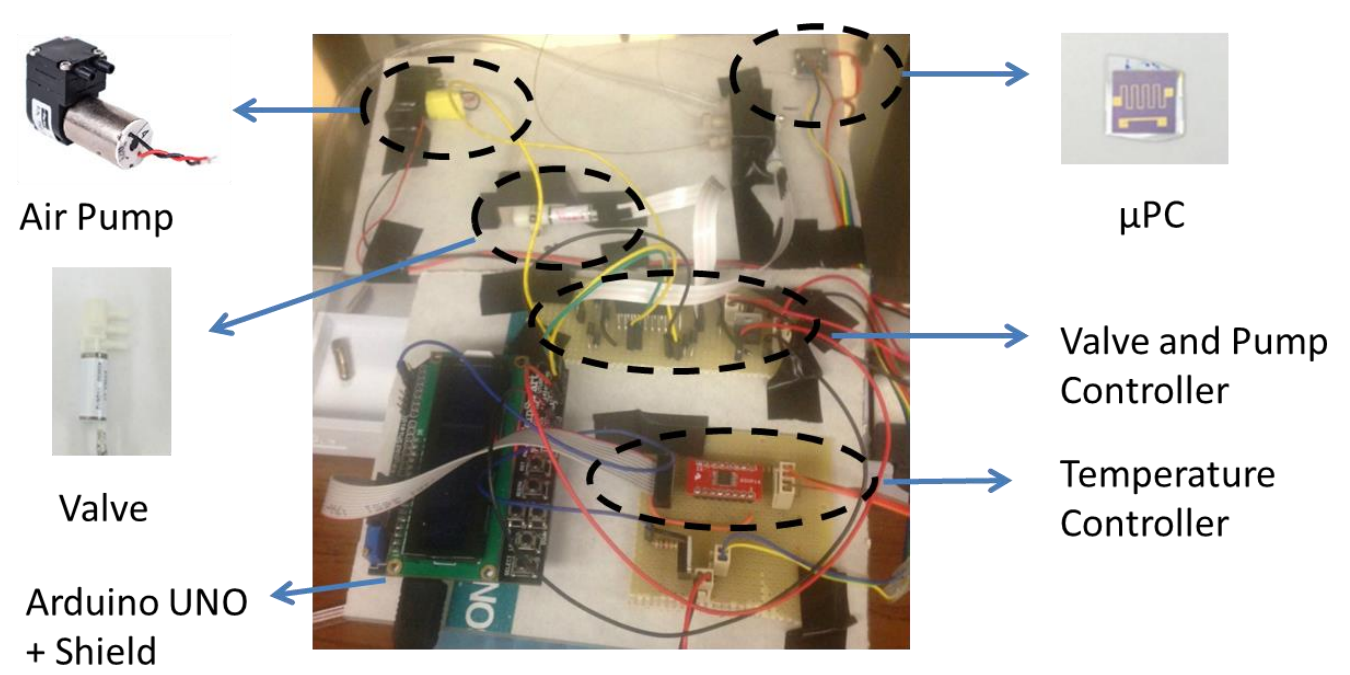

Figure 4-1 Arduino UNO based prototype (Photo by Apoorva Garg, 2014)

Due to limited capabilities of Arduino UNO in terms of number of peripherals, Arduino Mega 2560 was selected for the next prototype. A custom designed shield (Figure 4-2) for Arduino Mega was developed which incorporated temperature controllers, valves and pump controller, TCD interface and user interface circuitry. Integration of $\mu \mathrm{PC}$ and $\mu \mathrm{SC}$ TCD was tested with this setup. Basic end-to-end tests were performed, starting with loading the $\mu \mathrm{PC}$, followed by separation by $\mu \mathrm{SC}$ and detection of analytes by $\mu \mathrm{TCD}$. Once the integrated setup was tested, the final prototype of Zebra GC system was designed and developed, which is elaborated in the following section.

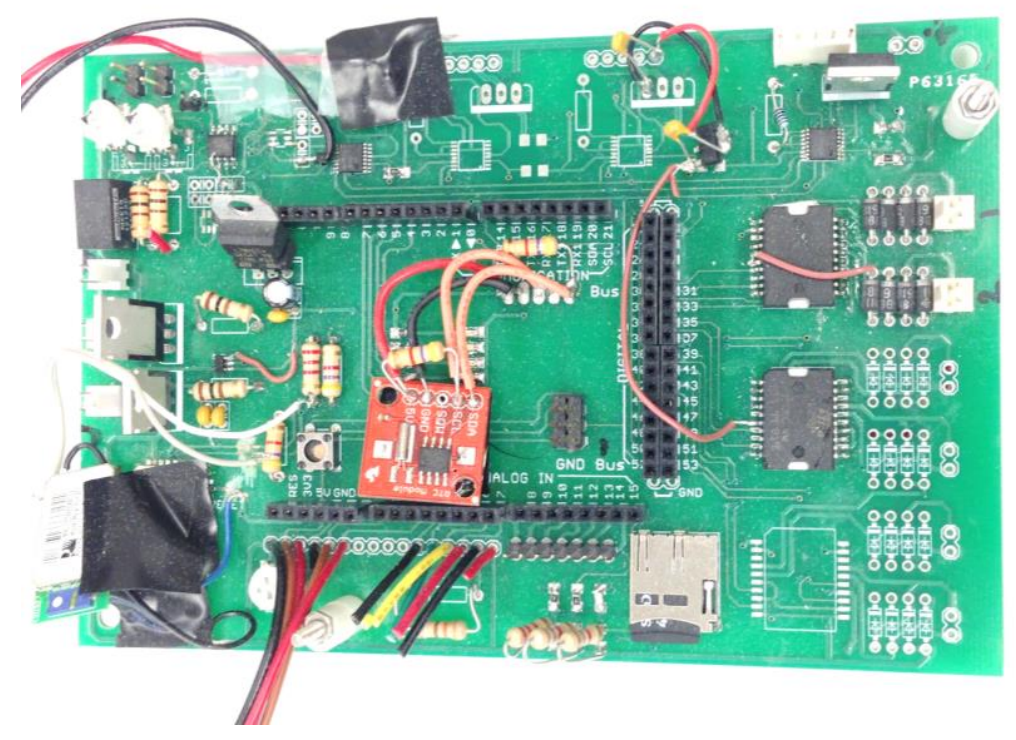

Figure 4-2 Arduino MEGA Shield for $\mu$ GC system (Photo by Apoorva Garg, 2014) 


\subsection{Zebra GC System}

Zebra GC system was implemented by vertically stacking human machine interface, $\mu$ Fluidic and integrated electronic module in a 12" $\times 6 " \times 4$ " box, as shown in Figure 4-3. The box also houses a lithium ion battery ( $2200 \mathrm{mAh}$ ) pack and a small helium cylinder ( $95 \mathrm{~mL}, 2700 \mathrm{psi}$ ) to make the device highly portable. System's sub-modules are described in the following sections.

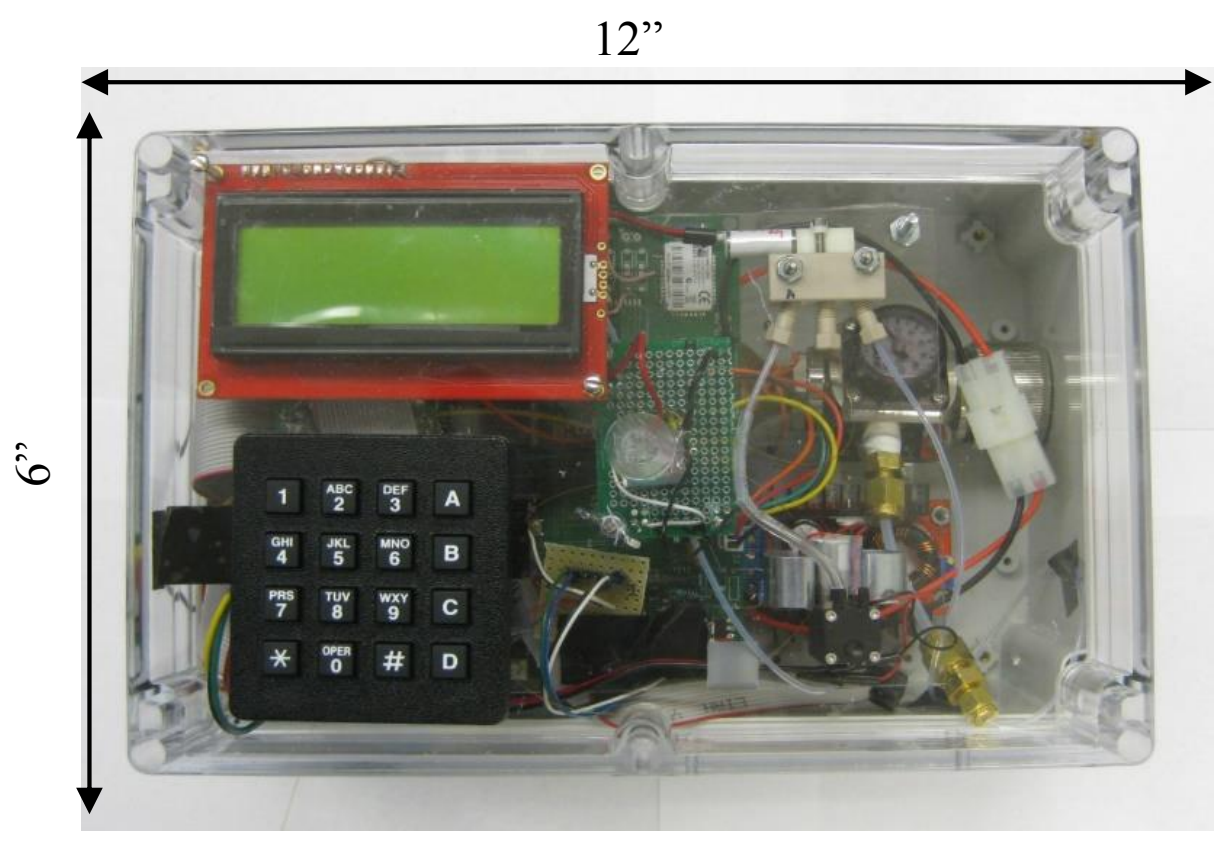

Figure 4-3 Zebra GC prototype (Photo by Apoorva Garg, 2014)

\subsection{1 $\mu$ Fluidic Module}

The $\mu$ Fluidic module houses all the microfabricated components along with flow controllers (pump and valves), to implement Zebra GC process flow schematic. MEMS chips were soldered to small general purpose printed circuit boards (PCB), which had cables connecting it to the integrated electronic module. The macro components were mechanically mounted on an Acrylic sheet, as shown in Figure 4-4. 


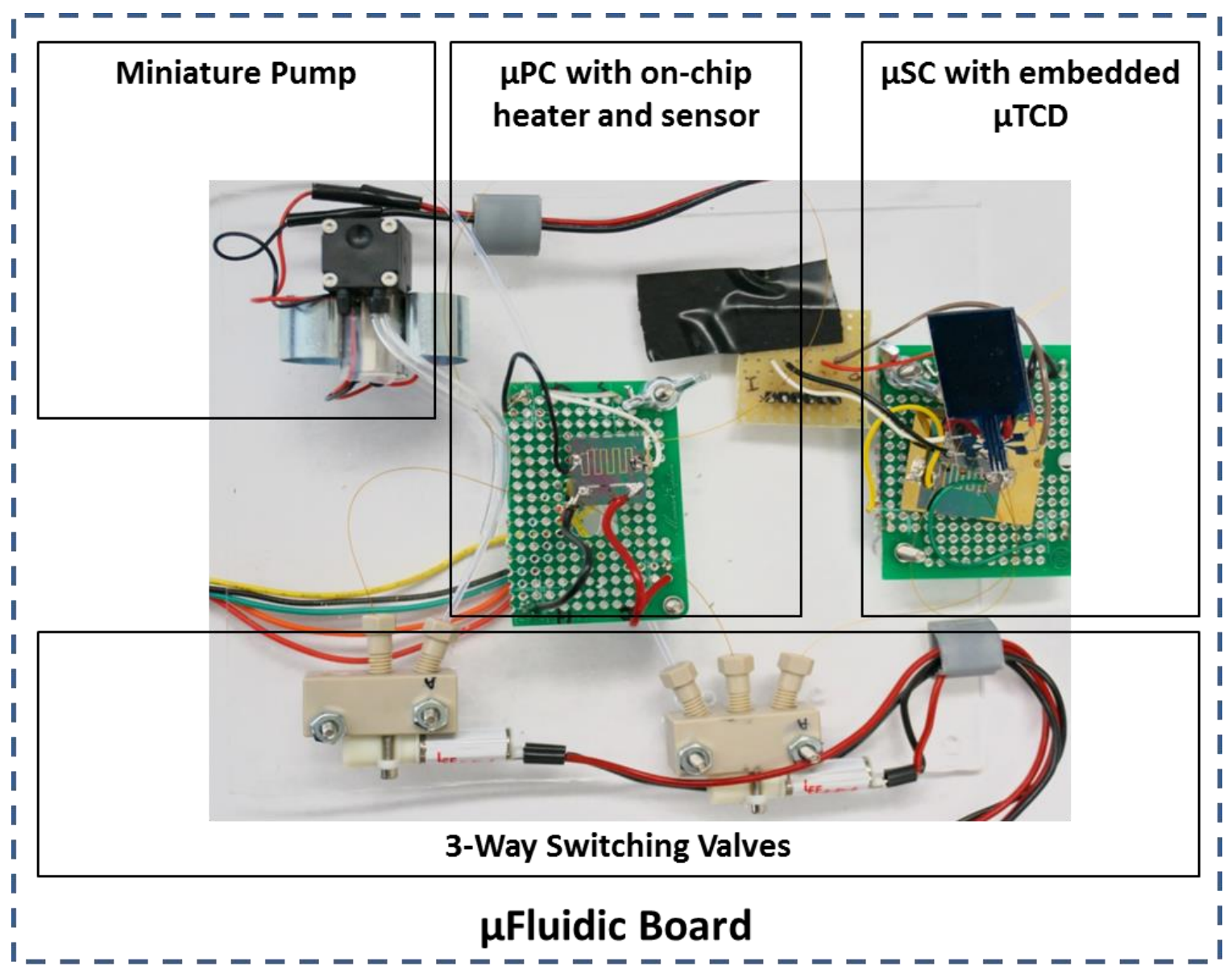

Figure 4-4 $\mu$ Fluidic Module (Photo by Apoorva Garg, 2014)

\subsubsection{Integrated Electronic Module}

The integrated electronic module implements the control and measurement circuitry for the components in $\mu$ Fluidic board. User interface and data acquisition circuitry are also integrated in this module. The circuits were fabricated on double-sided PCB boards, as shown in Figure 4-5, designed in Eagle CAD software. The interfacing connectors were kept on the edges of the board for clean connections to the $\mu$ Fluidic board.

This module is based on an 8-bit micro-controller, which co-ordinates all GC flow cycles and implements the user interfaces. A high-performance RISC-based micro-controller, ATmega640, was selected from Atmel's AVR series. The 100-pin micro-controller featured 15 PWM channels, 4 Universal asynchronous receiver/transmitter (UART) ports 
and 5 Serial Peripheral Interface (SPI) bus, which sufficed the peripheral requirements of target application and kept margin for future revisions. The device achieved a throughput of 16 MIPS being operated at $16 \mathrm{MHz}$.

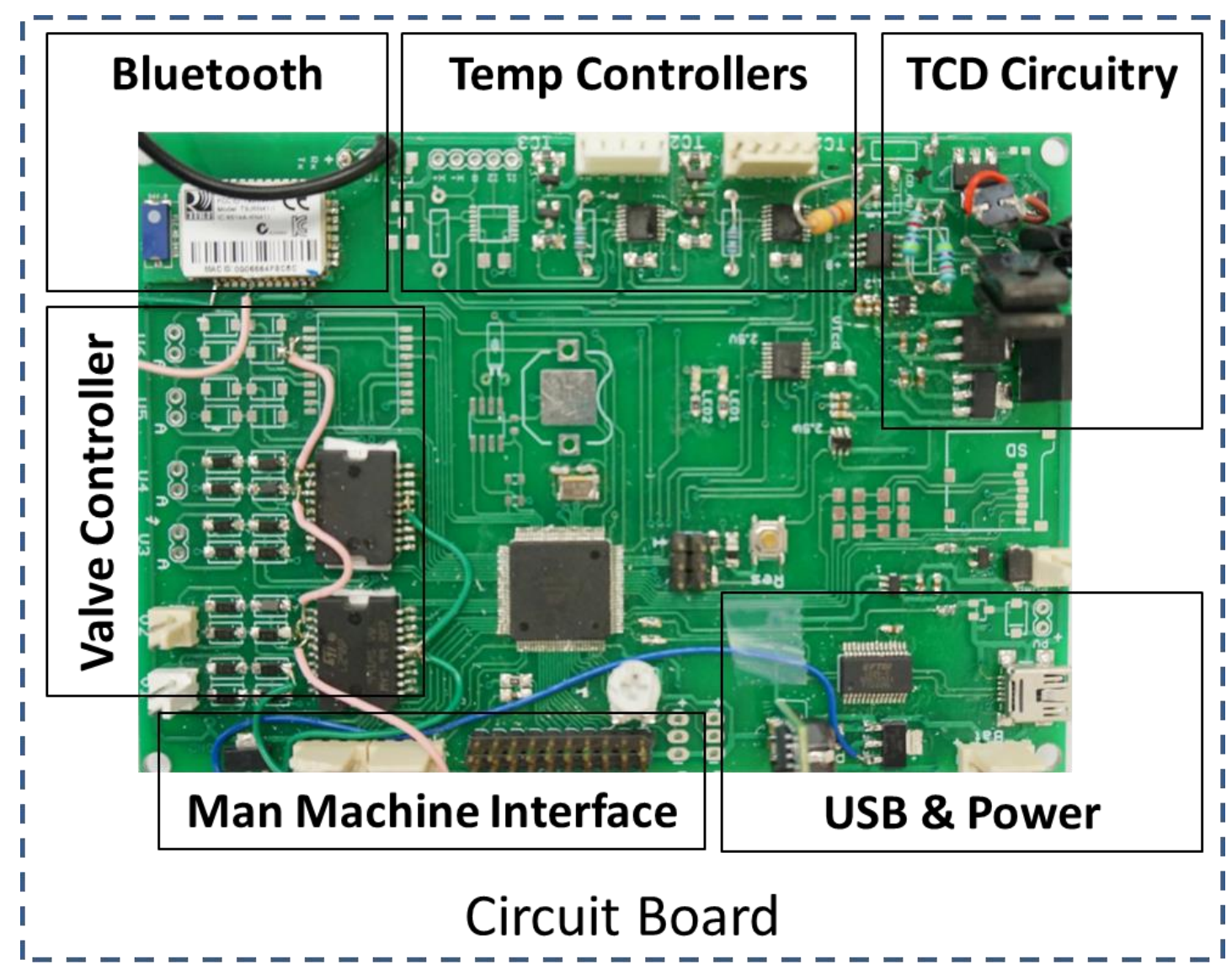

Figure 4-5 Integrated Electronic Module (Photo by Apoorva Garg, 2014)

\subsubsection{Embedded Firmware}

The embedded firmware was written in $\mathrm{C}$ and compiled using open source software development tools (WinAVR) for Atmel AVR. As show in the pseudo code (Figure 4-6), the firmware has 3 parallel flow of control. Timer and UART Interrupt Service Routine (ISR) are executed for Timer overflow and UART character receive-interrupts respectively. Initially, low level libraries were developed and tested for external peripherals like LCD, keypad, ADC and Bluetooth module. Following unit testing, the modules were 
integrated to implement the GC application. A set of AT commands were also implemented for device control and query.
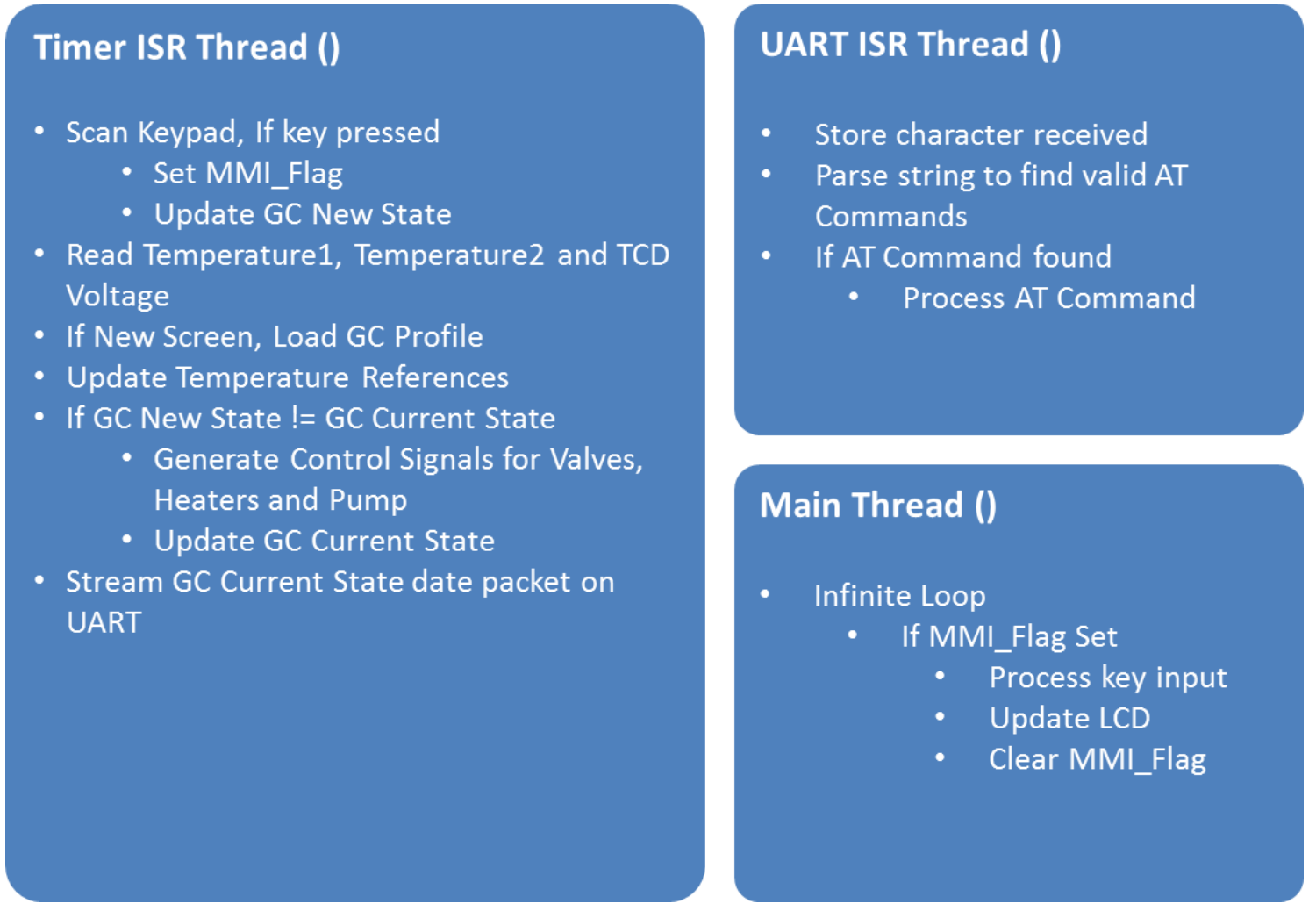

Figure 4-6 Embedded Firmware Pseudo Code

\subsubsection{Labview Application}

A Labview application (Figure 4-7) was developed for device control, data visualization, and recording. The application captures data received on the serial port of computer and processes the same for visualization and recording. It also features controls for automatically sending AT commands to the system. This completes the implementation details of the integrated Zebra GC system.

Chapter 5 shows the laboratory characterization and testing of the Zebra GC system for the target analytes and gasoline sample. 


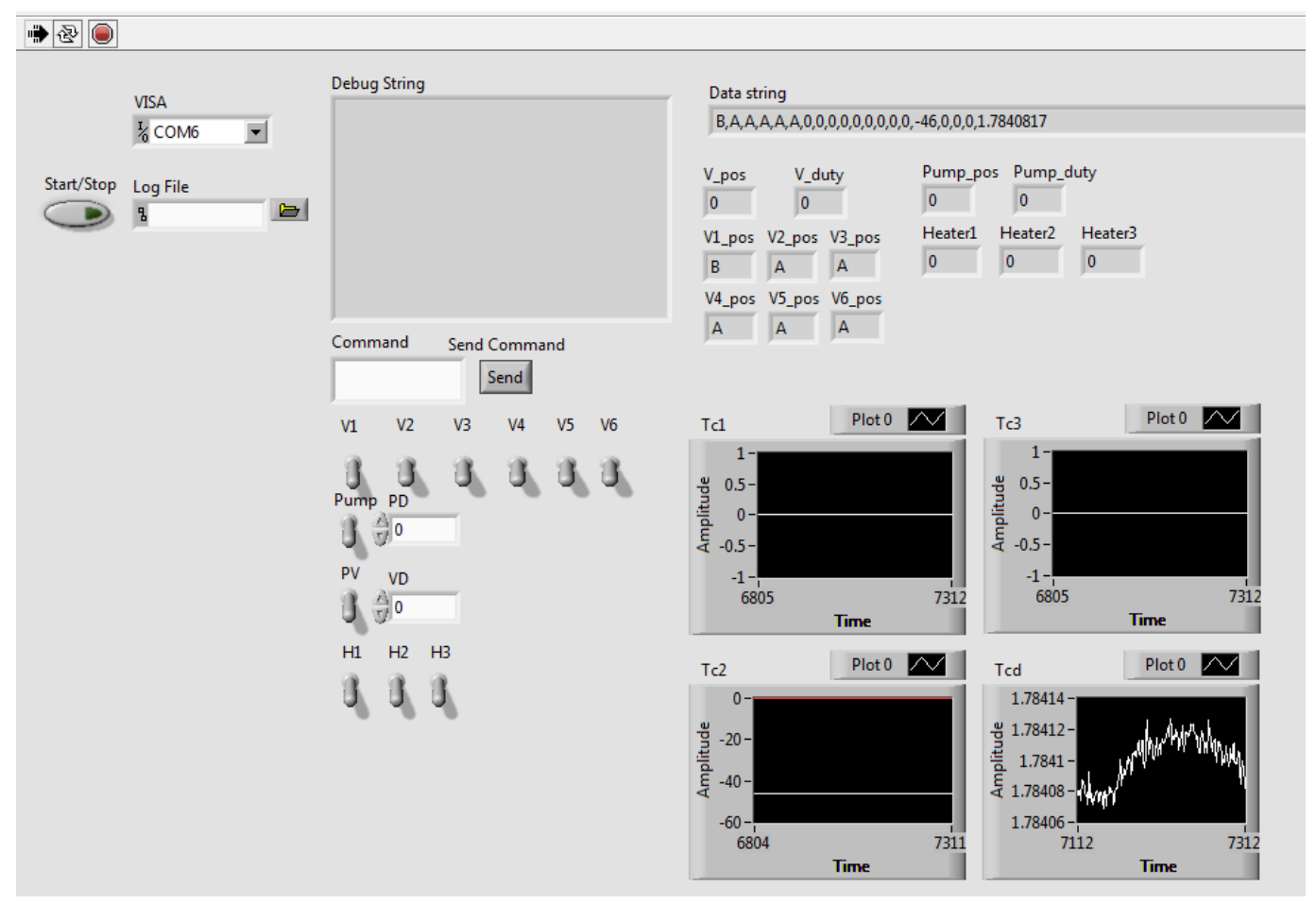

Figure 4-7 Screenshot of Labview Application 


\section{Results and Discussions}

Individual components were tested and characterized before integrating them to achieve a field deployable and fully-automated environmental monitoring Zebra GC system. The integrated system was characterized for target analytes followed by detailed comparison with conventional system for gasoline samples in simulated environment.

\subsection{Integrated Electronic Module Testing}

The electronic module primarily consists of temperature controllers, TCD interface, flow controllers, user interface, and data acquisition circuitry. Each module was tested and optimized separately before integration. On-chip heaters and sensors were used to control the temperature of $\mu \mathrm{PC}$ and $\mu \mathrm{SC}$. For accurate temperature measurement, on-chip sensors were calibrated by placing the MEMS devices in a commercial GC oven to characterize sensor resistance that responded linearly with respect to temperature with correlation coefficient $\left(R^{2}\right)>0.99$. The calibration was completed by updating the firmware with calibration slope and offset, which were computed from the resistance vs temperature table. The temperature profile required for $\mu \mathrm{PC}$ is very different from $\mu \mathrm{SC}$; the former requires heating at a high ramp rate $\left(20-100{ }^{\circ} \mathrm{C} / \mathrm{s}\right)$ to quickly desorb the analytes and generate a sharp injection plug, whereas the $\mu \mathrm{SC}$ requires heating at much lower ramp rates $(0.2-1$ ${ }^{\circ} \mathrm{C} / \mathrm{s}$ ) during the analysis phase to accelerate elution of high-molecular weight analytes. The $\mu \mathrm{PC}$ temperature reference was generated through the firmware, and a step reference was 
generated to heat the $\mu \mathrm{PC}$ to $200{ }^{\circ} \mathrm{C}$, which was sufficient to completely desorb ( 99\%) the analytes of interest. The ramp rate during heating depends on the thermal mass, power dissipation, and heat losses across the micro-device. Table 5-1 summarizes the average heating ramp rate and average power consumption for different heater voltages. As shown in Figure 5-1, the maximum heating ramp rate of the $\mu \mathrm{PC}$ was $25^{\circ} \mathrm{C} / \mathrm{s}$, achieved by applying $18 \mathrm{~V}$ DC across the heater resistance $(15 \Omega)$. Further increase in the voltage resulted in deterioration of heater thin film due to high current density, therefore the maximum heater voltage was kept at $18 \mathrm{~V}$. Figure 5-2 shows the temperature profile of $\mu \mathrm{SC}$ for ramp rates of $20^{\circ} \mathrm{C} / \mathrm{min}$ and $30^{\circ} \mathrm{C} / \mathrm{min}$. The power consumption was $0.5 \mathrm{~W}$ and $1.2 \mathrm{~W}$ for isothermal operation of $\mu \mathrm{SC}$ at $45^{\circ} \mathrm{C}$ and $65^{\circ} \mathrm{C}$, respectively.

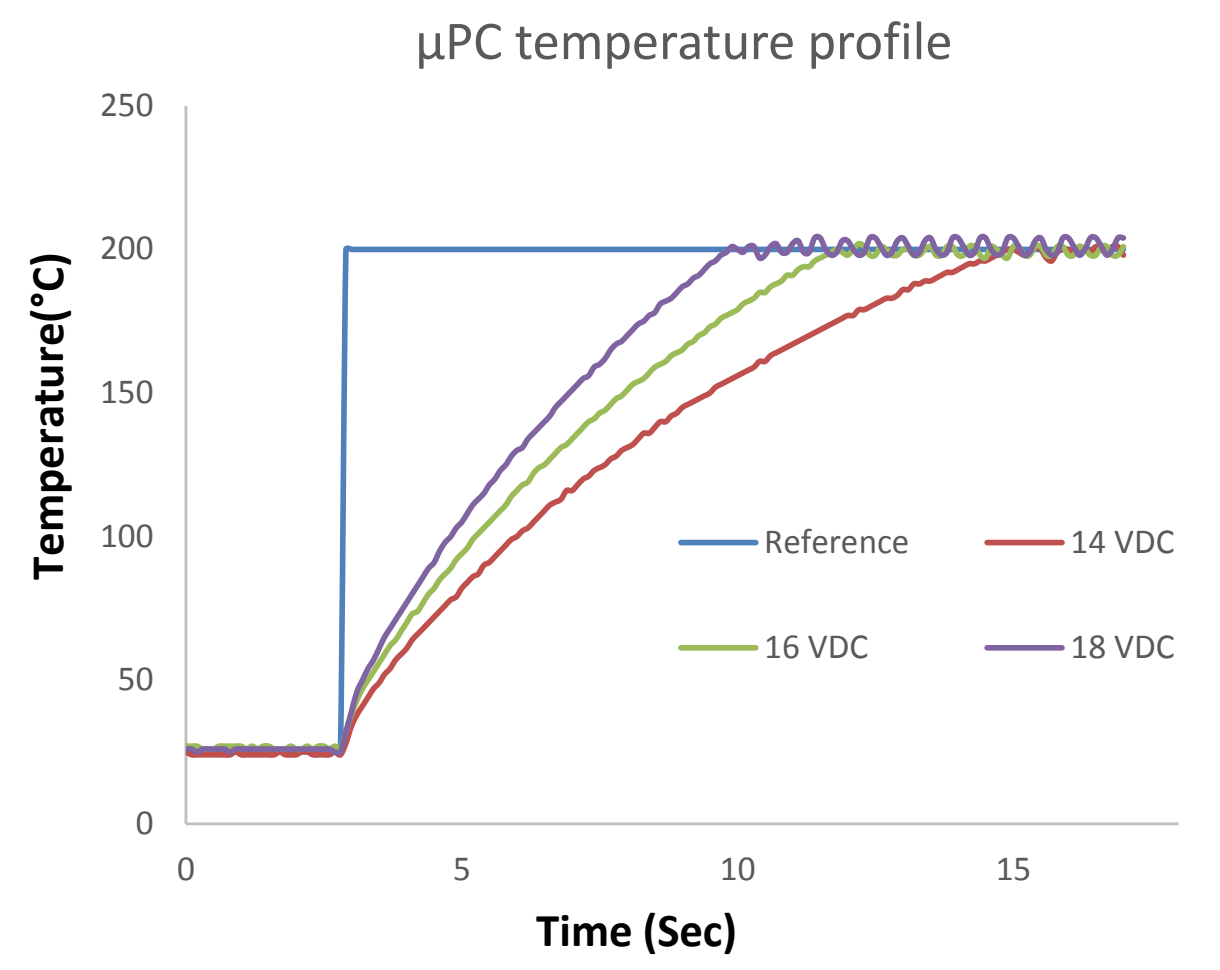

Figure 5-1 $\mu \mathrm{PC}$ temperature profile and effect of heater voltage on $\mu \mathrm{PC}$ heating 
Table 5-1 $\mu$ PC Average Ramp Rate and Power Consumption

\begin{tabular}{|l|c|c|}
\hline $\begin{array}{l}\text { Heater } \\
\text { Voltage(V) }\end{array}$ & $\begin{array}{l}\text { Average } \\
\text { Power(W) }\end{array}$ & $\begin{array}{l}\text { Average Ramp } \\
\text { Rate }\left({ }^{\circ} \mathbf{C} / \mathbf{s}\right)\end{array}$ \\
\hline 14 & 10.8 & 15 \\
\hline 16 & 13 & 20 \\
\hline 18 & 16 & 25 \\
\hline
\end{tabular}

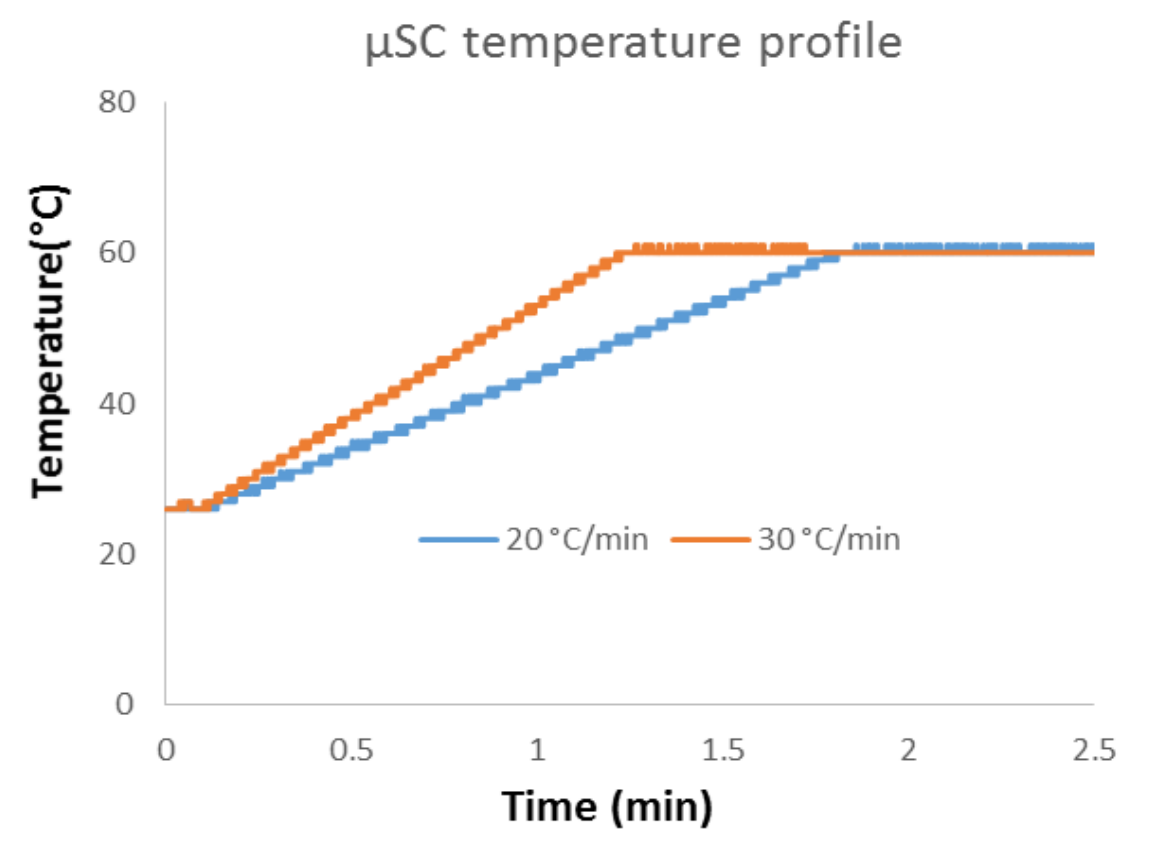

Figure 5-2 $\mu \mathrm{SC}$ temperature profile for ramp rate $20^{\circ} \mathrm{C} / \mathrm{min}$ and $30{ }^{\circ} \mathrm{C} / \mathrm{min}$

The $\mu$ TCD detector was connected in a Wheatstone bridge driven by $7.5 \mathrm{~V}$ and a thin film resistor (PF1260 series, Riedon Inc) which kept a low current noise. The sensitivity of the detector can be improved by increasing the signal-to-noise $(\mathrm{S} / \mathrm{N})$ ratio, by amplifying and filtering the signal. An ultra-low noise 24-bit ADC (AD7793, Analog Devices) was interfaced to the $\mu \mathrm{TCD}$, and an on-chip programmable gain amplifier and digital filters maximized the $\mathrm{S} / \mathrm{N}$ ratio. The amplifier gain was set to 32 and the on-chip Sinc3 digital 
filter was configured with an update rate of $10 \mathrm{~Hz}$, which rejected the broadband noise from the power supply, analog, and reference inputs. Once the operating parameters for the measurement circuitry were optimized, noise measurements were made under normal operating conditions with carrier gas flowing and $\mu$ TCD turned ON. The average peak-topeak detector noise was $8.08 \mu \mathrm{V}$, using the technique reported in [31], for baseline signal captured for $10 \mathrm{~s}$. The power consumption for $\mu$ TCD operation was $280 \mathrm{~mW}$. In the proposed $\mu \mathrm{GC}$ configuration, the miniature pump was connected to the outlet of the $\mu \mathrm{PC}$ which reduced sample contamination and minimized interference originating from the material of the pump's diaphragm. The loading flow rate for the present $\mu \mathrm{PC}$ was set to 1 $\mathrm{mL} / \mathrm{min}$, but flow rates as high as $35 \mathrm{~mL} / \mathrm{min}$ can be achieved for deep-etched variant of the $\mu \mathrm{PC}$ with the same setup. The power consumption for operating the miniature pump was $165 \mathrm{~mW}$.

As shown in Table 5-2, the power consumption of the $\mu \mathrm{GC}$ system was measured for different operation stages, by supplying it with $11.1 \mathrm{~V}$ (emulate Li-ion battery pack) from a DC power supply. The system had an average power consumption of $2.75 \mathrm{~W}$ and expected to last $\sim 8$ hours ( $\sim 10$ full cycles). Also, because each helium refill (95 mL, 2700 psi) will last $\sim 10,000$ full cycles, the size of helium cylinder can still considerably be reduced, and therefore, the overall size and form-factor of the $\mu \mathrm{GC}$ system can be even smaller.

Table 5-2 System power consumption for different stages

\begin{tabular}{|l|c|c|l|}
\hline Operating stage & Average Power(W) & Average Time(min) & Major Load \\
\hline Loading & 2.53 & 2 & Pump, interface circuitry \\
\hline Injection & 16.5 & 0.2 & $\mu \mathrm{PC}$ Heating \\
\hline Analysis & 2.2 & 2 & $\mu \mathrm{TCD}$, interface circuitry \\
\hline Cleaning & 16.5 & 0.2 & $\mu \mathrm{PC}$ Heating \\
\hline Full cycle & 2.75 & 4.4 & \\
\hline
\end{tabular}

\section{$5.2 \mu P C$ Testing}


For optimum operation, the $\mu \mathrm{PC}$ was characterized against four important parameters: adsorption capacity, breakthrough volume, desorption peak width, and desorption efficiency. The following subsections describe the testing procedure for the characterization of $\mu \mathrm{PC}$ for four analytes including benzene, toluene, chlorobenzene, and ethylbenzene.

\subsubsection{Adsorption capacity}

The adsorption capacity is the maximum amount of analyte that can be retained by the adsorbent bed. Among other factors governing adsorption, the flow rate during adsorption and the physico-chemical properties of the analyte strongly affect the amount retained by the sorbent bed. During adsorption at high flow rate, the time that the analyte spent in the $\mu \mathrm{PC}$ (residence time) becomes shortened. This decreases the interaction of the analyte with the active surface area on the sorbent bed of the $\mu \mathrm{PC}$ resulting in lower adsorption efficiency. To evaluate the maximum adsorption capacity of the $\mu \mathrm{PC}$ and to minimize the effect of flow rate, a flow rate of $1 \mathrm{~mL} / \mathrm{min}$ was used during adsorption. For testing the device, the $\mu \mathrm{PC}$ was connected between the injector and the FID of the conventional GC system. Headspace of the analytes in a sealed 1-mL vial was injected into the $\mu$ PC using an auto-sampler module. Assuming ideal gas law behavior, the amount of analyte injected from the vapor at equilibrium above the pure liquid was calculated taking into account the split ratio and the injection volume. The split ratio and the injection volume were changed to vary the amount of analyte introduced into the $\mu \mathrm{PC}$. Analytes not retained by the adsorbent bed appear as breakthrough peak. The $\mu \mathrm{PC}$ is heated to desorb the retained compound which appears as desorption peak. Concentration of the non-retained and the retained analytes were calculated by integrating the area under the peaks. The adsorption efficiency was determined as percentage of the desorption peak area relative to the sum of the breakthrough and the desorption peak areas. The point corresponding to $90 \%$ adsorption efficiency (10\% appears as breakthrough area) was defined as the maximum capacity of the $\mu \mathrm{PC}$ for a particular analyte.

Adsorption capacity was evaluated for four different analytes including benzene, toluene, chlorobenzene and ethylbenzene. Figure 5-3a illustrates that the $\mu \mathrm{PC}$ can adsorb $\sim 30-400$ $\mathrm{ng}$ of analytes depending on their affinity to Tenax TA. The masses retained were $\sim 30 \mathrm{ng}$, 
$130 \mathrm{ng}, 240 \mathrm{ng}$, and $350 \mathrm{ng}$ for benzene, toluene, chlorobenzene, and ethylbenzene, respectively. These results indicate that the $\mu \mathrm{PC}$ can retain sufficient amount of compound well above the detection limit of our $\mu$ TCD $(\sim 1 \mathrm{ng})$. The results also show that Tenax TA retains compounds with high boiling points more effectively as compared to those with low boiling points such as benzene. At a specific partial pressure, the more volatile analytes have reduced interaction with the sorbent resulting in lower amount of analytes being adsorb. Nevertheless, the amount of benzene retained by the $\mu \mathrm{PC}$ is still above the detection limit for benzene using the $\mu \mathrm{GC}$.

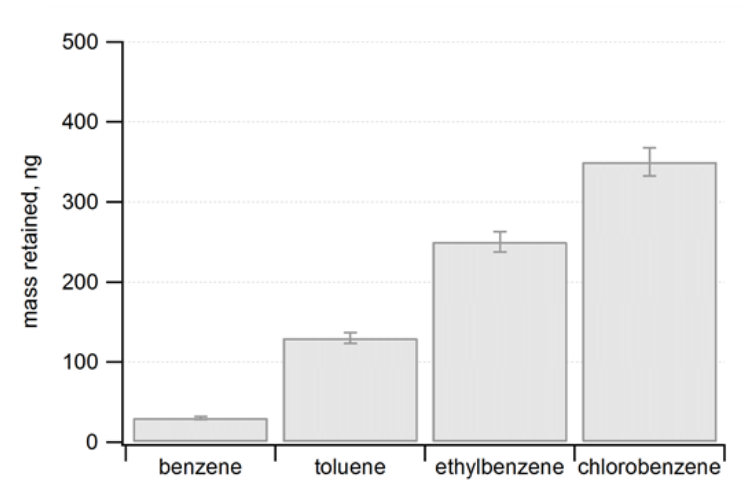

(a) Maximum amount of test components retained in the $\mu \mathrm{PC}$

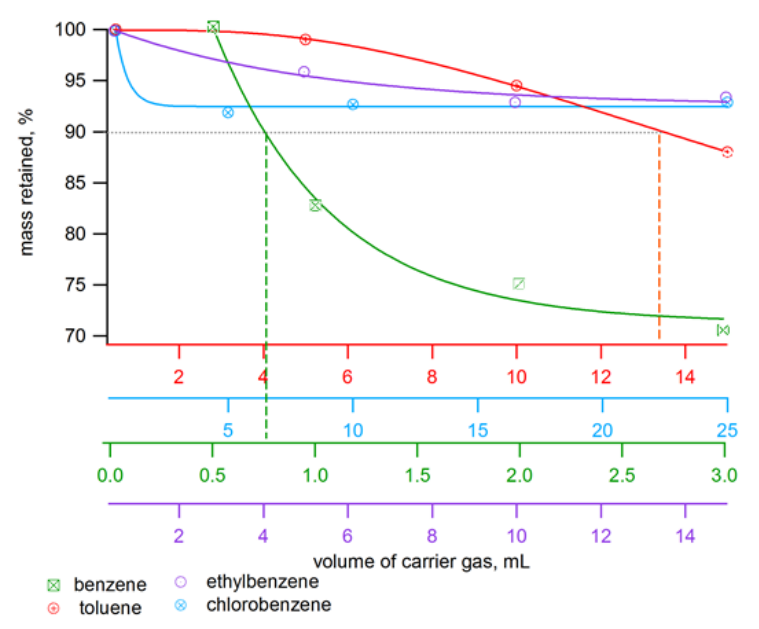

(b) BV10 curves for benzene, toluene, chlorobenzene, and ethylbenzene. Dash lines represent breakthrough volumes.

Figure 5-3 $\mu$ PC sample capacity and breakthrough volume 


\subsubsection{Breakthrough volume (BV)}

The volume of carrier gas required to remove $10 \%$ of the retained analyte from the adsorbent is the BV. Determination of BV is crucial and ensures that the analytes of interest are not purged off from the sorbent bed because of the flow of the carrier gas during the sampling. We measured BV by connecting the $\mu \mathrm{PC}$ between the injector and FID ports of a conventional GC system. First, approximately $4 \mathrm{ng}$ of each analytes was loaded separately on the $\mu \mathrm{PC}$ at flow rate of $1 \mathrm{~mL} / \mathrm{min}$. After adsorption, the $\mu \mathrm{PC}$ was thermally desorbed and the area under the desorption peak which represents the total mass retained by the adsorbent was integrated. Similar procedure was repeated, but after injection, 5, 10, 15,25 , and $30 \mathrm{~mL}$ of the carrier gas was passed through the $\mu \mathrm{PC}$ at a flow rate of $1 \mathrm{~mL} / \mathrm{min}$. The $\mu \mathrm{PC}$ was subsequently heated and the volume of carrier gas which resulted in a $10 \%$ reduction in the total mass retained was noted. Figure 5-3b illustrates that for four of the compounds tested only benzene has a $B V$ less than $1 \mathrm{~mL}$, toluene has $B V$ of $13 \mathrm{~mL}$, while chlorobenzene and ethylbenzene has $B V_{10}$ above the typical volume sampled in our experiments $(15 \mathrm{~mL})$.

\subsubsection{Desorption peak width and desorption efficiency}

The chromatographic resolution of a separation column highly depends on the width of injection plug. In the proposed $\mu \mathrm{GC}$ architecture, $\mu \mathrm{PC}$ serves the dual role of injector also, therefore the desorption peak from $\mu \mathrm{PC}$ is an essential parameter having significant effect on system's performance. For a given adsorbent bed, the desorption peak width depends on the heating ramp rate, the final temperature, and the flow rate.

The desorption peak width was characterized by adsorbing the analyte onto the $\mu \mathrm{PC}$ connected between the injector and FID ports of the conventional GC system and subsequently heated using on-chip heater equipped with temperature sensors. As shown in Figure 5-4, the initial desorption peak width attained at a ramp rate of $25^{\circ} \mathrm{C} / \mathrm{s}$ was $\sim 4 \mathrm{~s}$ resulting in a good chromatographic separation. The desorption peak width was further optimized by flow manipulation technique. In this technique, analytes are desorbed by heating the $\mu \mathrm{PC}$ in the absence of a flow of the carrier gas. Once the maximum temperature 
of $200{ }^{\circ} \mathrm{C}$ was attained, the carrier gas was passed through the $\mu \mathrm{PC}$ resulting in a reduction in the peak width at half height (PWHH) from $4 \mathrm{~s}$ to $\sim 350 \mathrm{~ms}$ The PWWH attained is similar across all the analytes considered in this study.

Additionally, a 99\% desorption efficiency for the analyte of interest was achieved by heating the $\mu \mathrm{PC}$ to $200^{\circ} \mathrm{C}$. The remaining amount was removed by subsequent heating of the $\mu \mathrm{PC}$ prior to another run to minimize carry over from the previous adsorption run. The desorption temperature of $200{ }^{\circ} \mathrm{C}$ was selected to minimize degradation of the adsorbent bed (maximum operating temperature for Tenax TA is $350^{\circ} \mathrm{C}$ ) and the analytes.

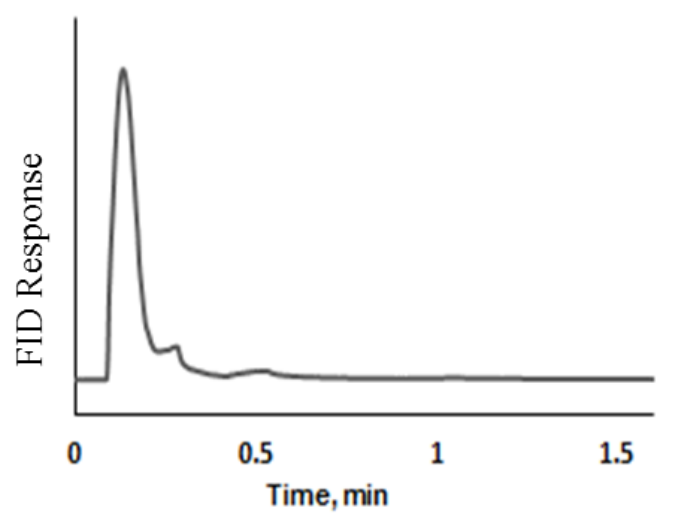

(a) $\mu \mathrm{PC}$ desorption profile

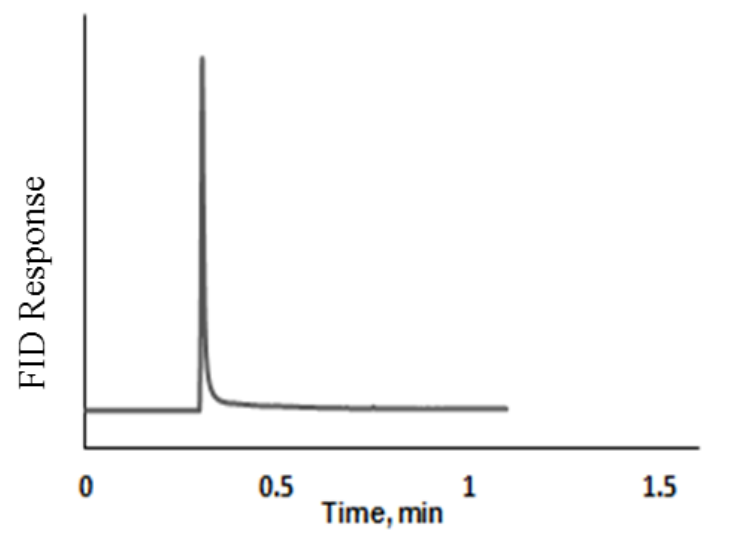

(b) $\mu \mathrm{PC}$ desorption profile using flow manipulation technique.

Figure 5-4 $\mu \mathrm{PC}$ desorption peak profile

\section{$5.3 \mu S C$-TCD Testing}

The 2-m length of the $\mu \mathrm{SC}$ was selected to ensure good separation and short analysis times. The efficiency of the coated column was evaluated with $\mu$ TCD switched to ON condition by applying 7.5 V DC to the Wheatstone bridge. This voltage corresponds to a temperature of $80{ }^{\circ} \mathrm{C}$ for the $\mu \mathrm{TCD}$ and was measured with helium flowing $(\sim 0.7 \mathrm{~mL} / \mathrm{min})$, using method reported previously [32]. The heated $\mu$ TCD elevated the temperature of the column to $32{ }^{\circ} \mathrm{C}$. The metric commonly used for column performance is height equivalent to a theoretical plate (HETP), 


$$
\operatorname{HETP}=\frac{\mathrm{L}}{\mathrm{N}}
$$

Where, $\mathrm{L}$ is the length of column and $\mathrm{N}$ is the number of theoretical plates in the column. $\mathrm{N}$ is calculated experimentally from peak retention time $\left(\mathrm{t}_{\mathrm{r}}\right)$ and peak width at half height $\left(\mathrm{w}_{1 / 2}\right)$.

$$
\mathrm{N}=5.54\left[\frac{\mathrm{t}_{\mathrm{r}}}{\mathrm{w}_{1 / 2}}\right]^{2}
$$

The plate number was calculated over a range of column pressures using method reported in our previous work [33]. The maximum plate number (optimum condition) observed was $\sim 6200$ for 2 -m long column at 12 psi (flow rate $0.7 \mathrm{~mL} / \mathrm{min}$ ).

Further, we tested the separation and identification of six VOCs using the column and its $\mu \mathrm{TCD}$. The $\mu \mathrm{SC}$ along with the interface circuitry was installed inside a conventional GC (7890, Agilent, Palo Alto, CA) and connected to the injection port and FID with fusedsilica capillaries. FID was used to verify the chromatogram generated by the $\mu$ TCD. A mixture of six compounds (saturated headspace), containing benzene, toluene, tetrachloroethylene, chlorobenzene, ethylbenzene, and $p$-xylene, was injected by autosampler through the heated injection port $(1 \mu \mathrm{l}, 50: 1 \mathrm{split}$ ratio $)$ at $0.7 \mathrm{~mL} / \mathrm{min}$. The peaks were found to be well resolved and the separation required less than 2 minutes. Next, a calibration curve showing the output (peak area) of the $\mu$ TCD as a function of the VOC's injected mass was obtained. For that purpose, saturated headspace sample for each VOC was prepared and tested. The split ratio was varied from 120:1 to 50:1 based on the vapor pressure of the VOC. Injected volumes were varied from $0.5 \mu \mathrm{L}$ to $4 \mu \mathrm{L}$, to get the mass injected in the range $\sim 1$ to $5 \mathrm{ng}$, where mass calculations were performed by using the saturated vapor pressure, injected volume and split ratio for each VOC. A calibration curve showing the average peak area vs injected mass for three injections is shown in Figure 5-5. Results obtained indicate a linear response of the $\mu$ TCD for each VOC with relative standard deviation (RSD) less than $10 \%$ (maximum 6.2\%) for all cases. The $R^{2}$ value was greater than 0.99 in all cases. 


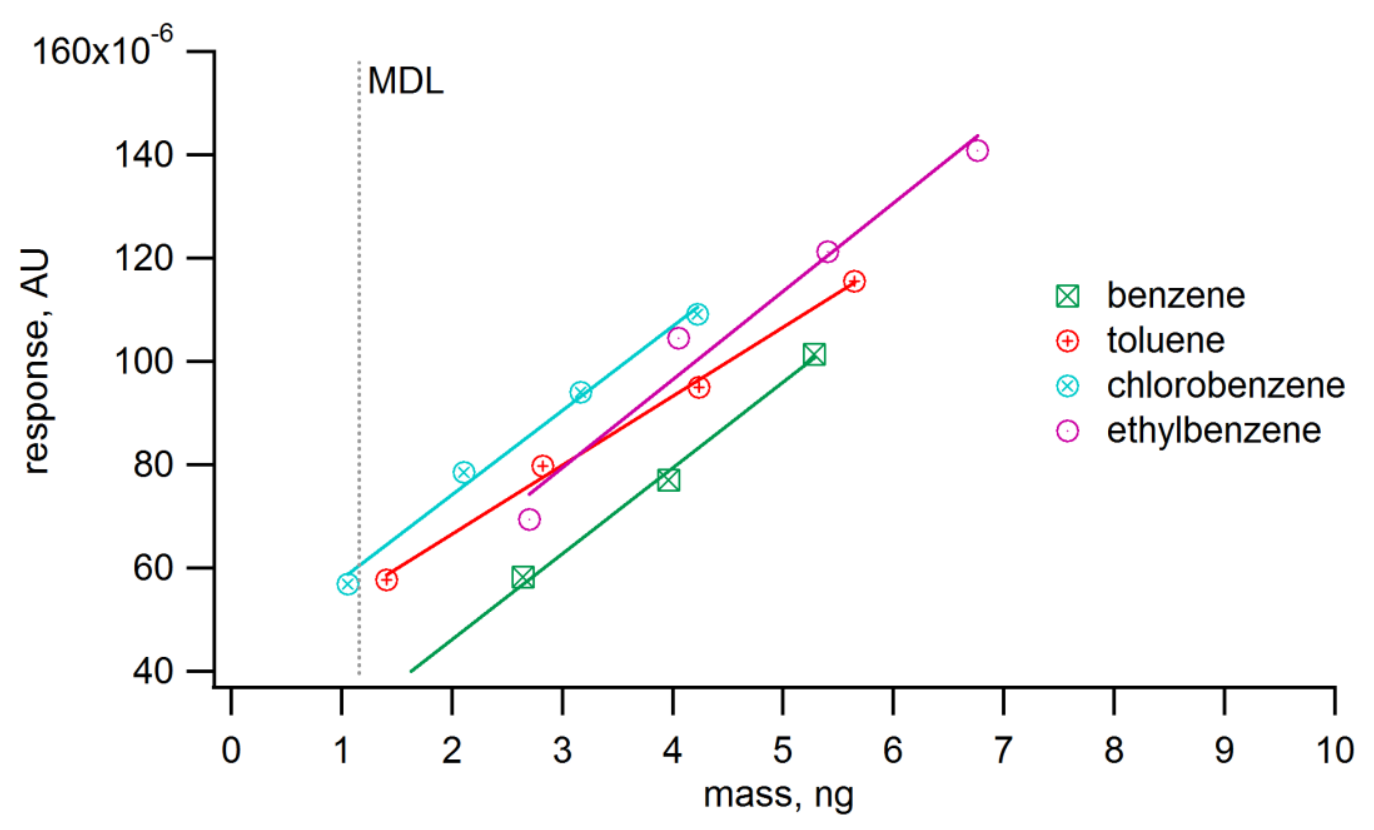

Figure 5-5 Minimum detectable limit (MDL) for test compounds by $\mu$ TCD

\subsection{Integration of $\mu P C$ and $\mu S C-T C D$}

Once individual chips were tested and characterized, the $\mu \mathrm{PC}$ was connected upstream of $\mu \mathrm{SC}-\mathrm{TCD}$ to test the hybrid integration. The integration was expected to both improve and compromise the system performance on different aspects of the $\mu \mathrm{GC}$. The compact design reduced the transfer lines, thereby reducing the formation of cold spot that decreases efficiency. On the other hand, the optimal flow rate for operating the $\mu \mathrm{PC}$ and $\mu \mathrm{SC}$ were different, therefore, trade-off in establishing the flow rate for the integrated system exist. The inlet port of $\mu \mathrm{PC}$ was connected to the $\mathrm{GC}$ injector $\left(280^{\circ} \mathrm{C}\right.$, split ratio $\left.50: 1\right)$ and it was loaded with mixture containing six compounds (equilibrium headspace, $1 \mu \mathrm{L}$ ). For initial testing, the outlet port of $\mu \mathrm{SC}$ was connected to the FID detector of conventional GC. The flow rate was set to $1 \mathrm{~mL} / \mathrm{min}$, for which the PWHH was measured to be $0.8 \mathrm{~s}$ from the $\mu \mathrm{PC}$ and the $\mu \mathrm{SC}$ exhibited well resolved peaks for the analytes of interest. As shown in Figure 5-6, the six compounds were separated and identified in less than 2 minutes. 
TCD is sensitive to flow perturbation during the switching of carrier gas into the $\mu \mathrm{PC}$, therefore, the integrated $\mu \mathrm{TCD}$ presented some challenges because of interference stemming from the injection of the analyte to the $\mu \mathrm{PC}$. The problem was solved by adopting innovative system architecture. As shown in Figure 3-10, an alternate flow path for the $\mu \mathrm{PC}$ was provided to maintain a steady flow in $\mu$ SC-TCD during injection cycle. The fluidic resistance of the alternate flow path was matched closely with the $\mu$ PC path to minimize flow perturbation while switching between the two paths. The new architecture decreased the $\mu$ TCD stabilization time by one order of magnitude (from 1-2 min to $10 \mathrm{~s}$ ) and ensures continuous flow of carrier gas. As shown in Figure 5-7, 5 out of 6 compounds tested were easily identified.
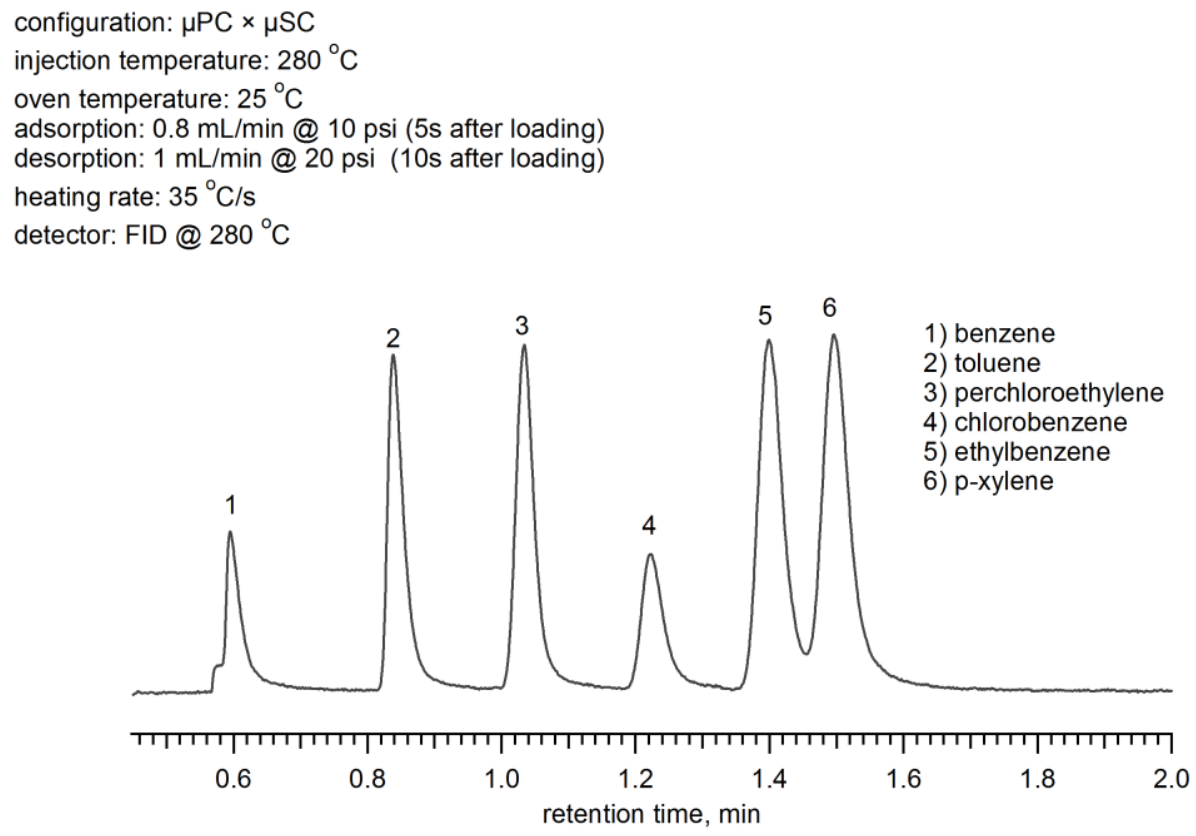

Figure 5-6 Separation of test compounds with integrated $\mu \mathrm{PC}$ and $\mu \mathrm{SC}$

\subsection{Microsystem Testing, Calibration and Evaluation}

The components of the microsystem were assembled as schematically shown in Figure 3-10. In addition to the integration of $\mu \mathrm{PC}$ and $\mu \mathrm{SC}$ mentioned above, a Y-connector was 
added between them to connect the miniature pump through a valve. The connector isolated the loading path of the $\mu \mathrm{PC}$ from the $\mu \mathrm{SC}$, which reduced contamination to the $\mu \mathrm{SC}$. This also permits loading at higher flow rates to the $\mu \mathrm{PC}$ since the high fluidic resistance in the $\mu \mathrm{SC}$ was avoided. The initial design had a solenoid valve between the $\mu \mathrm{PC}$ and the $\mu \mathrm{SC}$, but was modified because the valves had $\sim 10 \mu \mathrm{L}$ internal volume that increased the dead volume and deteriorated the width of the injection plug from the $\mu \mathrm{PC}$.

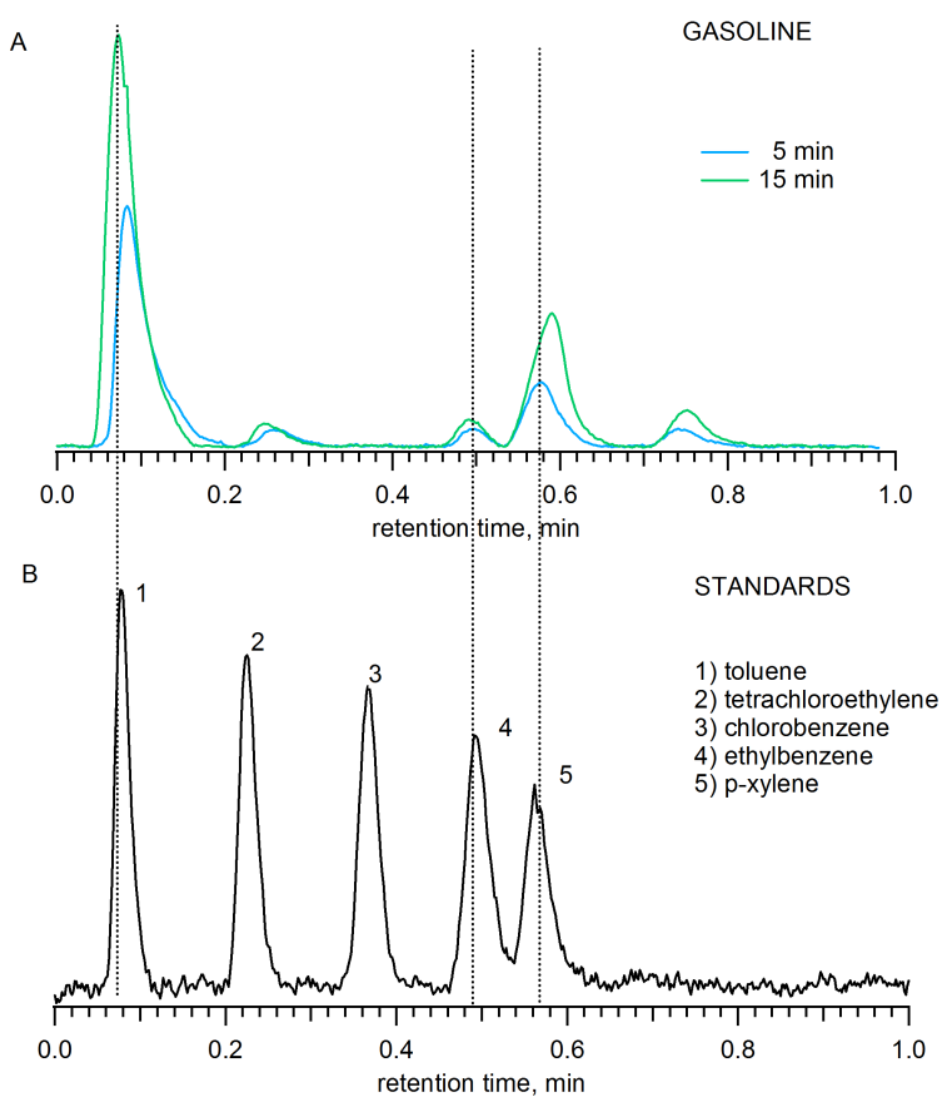

Figure 5-7 Chromatogram of (A) gasoline vapor and (B) standards using $\mu \mathrm{GC}$

The microsystem was tested by loading the system with a mixture of five compounds (headspace), containing toluene, tetrachloroethylene, chlorobenzene, ethylbenzene, and $p$ xylene, injected by the GC autosampler through the heated injection port $(2 \mu \mathrm{L}, 40: 1$ split ratio) at $0.7 \mathrm{~mL} / \mathrm{min}$. As shown in Figure 5-7B, calibration standards were generated with this method. The injected mass ranged from $1-3 \mathrm{ng}$, which is equivalent to $10 \mathrm{~mL}$ loading of $\sim 100 \mathrm{ppbv}$ gas mixture, approximating a 10-min loading using a pump operated at 1 
$\mathrm{mL} / \mathrm{min}$. The tests were performed three times. The repeatability of the retention time repeatability was $<1.3 \%$ (RSD) for all analytes. The peak areas and peak height had average RSD of $<4.7 \%$ and $8 \%$, respectively.

Finally, the fully-assembled $\mu \mathrm{GC}$ system was evaluated using gasoline as the test sample. The test atmosphere was generated by placing $50 \mathrm{~mL}$ of gasoline in a $100 \mathrm{~mL}$ beaker which was placed inside a large glass chamber $(\sim 4 \mathrm{~L})$. Air was circulated inside the chamber but outside the gasoline beaker at $500 \mathrm{~mL} / \mathrm{min}$ to simulate a car refueling scenario. The top of the chamber was kept open to the atmosphere and the chamber was allowed to be filled with vapors for 10 minutes. The vapors were sampled through the $\mu \mathrm{GC}$ system, by keeping the system's inlet close to the top of the chamber. Vapors were sampled at ambient temperature and pressure for two different sampling times, 5 and 15 minutes. To compare results with a conventional sampling system, gasoline vapors were also sampled using sorbent tubes packed with Tenax TA ( 200mg) at a sampling flow rate of $69 \mathrm{~mL} / \mathrm{min}$ for 3 hours. Approximately 12.4 L of gasoline vapor were collected in the sorbent tubes. Sorbent tubes were desorbed using a thermal desorption system coupled to a GC-FID (TDGC-FID, Perkin-Elmer ATD 400) having a conventional column. Toluene and $p$-xylene were identified with concentration of 16 and 14 ppmv, respectively (Figure 5-8). In both systems ( $\mu$ GC and ATD-GC-FID), benzene was not identified because it co-elutes with the other low-boiling point components in gasoline. Figure 5-7A illustrates that the $\mu \mathrm{GC}$ system detected five peaks; three of those were identified as toluene, ethylbenzene, and $p$ xylene. Also, because Tenax TA has low affinity to benzene, the $\mu$ GC system retained lesser mass as compared to the other analytes. The sample volume collected and analyzed in the $\mu \mathrm{GC}$ was $\sim 3$ orders of magnitude lower than those collected on sorbent tubes. These results illustrate that the $\mu \mathrm{GC}$ system is capable of detecting and separating compound with much shorter sampling time and low sample volume compared to conventional system to complete one full cycle of analysis. 


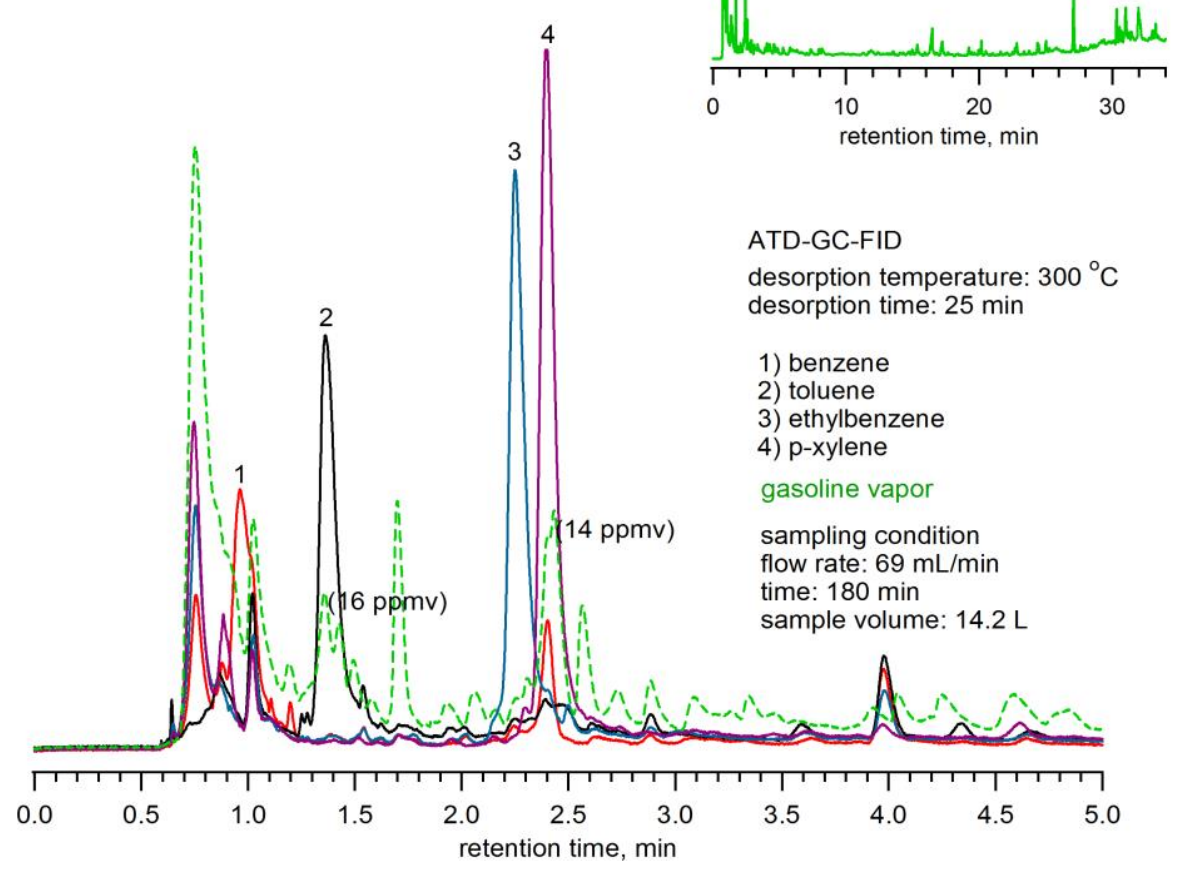

Figure 5-8 Chromatogram of gasoline vapor (green) and standards 


\section{Conclusion}

In this thesis, we showed prototypal implementation of a $\mu \mathrm{GC}$ system suitable for environment monitoring applications. The system leverages micro-machined components to achieve lower power consumption, smaller form factor and faster analysis time over conventional systems. Monolithic integration of $\mu$ SC and $\mu$ TCD leads to reduction in chipto-chip interfaces, thereby reducing chances of cold spot efficiency reduction and lowering maintenance cost.

The architecture also included a novel method to perform injections with a very sharp plug from the $\mu \mathrm{PC}$ even in the presence of flow-sensitive gas detectors like TCD. The proposed method decoupled the effect of vapor desorption time on desorption peak width, thereby relaxing the constraints on $\mu \mathrm{PC}$ design. Extensive laboratory characterization of the system was performed for four VOCs identified as HAPs. A detailed comparison of the $\mu \mathrm{GC}$ system is reported against conventional ATD-GC-FID system for real gasoline samples in simulated field environment, highlighting the advantages of such application specific $\mu \mathrm{GC}$ systems over conventional ones.

\subsection{Future Work}

The reported prototypal $\mu \mathrm{GC}$ implementation can be further improved by making design changes. Firstly, the deep-etched $\mu \mathrm{PC}$ can be integrated in the system. This will enable high sample volume and can possibly reduce loading time by enabling loading at higher flow rates. Next, innovative column configurations can be utilized to improve separation 
efficiency and reduce power consumption and analysis time. Semi-packed and multicapillary column can be incorporated in the subsequent versions for improved efficiency.

One of the disadvantages of embedding $\mu \mathrm{TCD}$ in $\mu \mathrm{SC}$ is the shift in TCD baseline due to thermal crosstalk during temperature programming of $\mu \mathrm{SC}$. The TCD baselines signal is:

$$
\text { Vsignal }=\text { Vbridge } \times(R t c d 1-R t c d 2) /(R+R t c d)
$$

Where Rtcd 1 and Rtcd 2 are the resistances of output and reference detectors, Rtcd is the average value of TCD resistors, $\mathrm{R}$ is the external resistance and Vbridge is the voltage applied at Wheatstone bridge's head. As shown in the equation below, the change in temperature effects the value of Rtcd 1 and Rtcd 2 only:

$$
\text { Vsignal } \propto \operatorname{Rtcd} 1(1+\alpha 1 \times \Delta T)-\operatorname{Rtcd} 2(1+\alpha 2 \times \Delta T)
$$

Therefore the drift in the signal can be computed to be dependent on:

$$
\Delta V \text { signal } \propto \Delta T(\alpha 1 \times R t c d 1-\alpha 2 \times R t c d 2)
$$

The thermal crosstalk can be minimized in two ways. Assuming similar temperature coefficient for the two TCD resistors as they are based on same material, the drift will be directly proportional to the difference in TCD's resistances, and can be minimized by matching both the resistors closely. Also, the temperature control system of the $\mu \mathrm{SC}$ can be tuned to produce minimal temperature fluctuations during isothermal operation. One possible way to minimize temperature fluctuations is that the controller output can be locked to the average value before starting $\mu$ TCD's signal measurement.

The system can be further evaluated by comparing its accuracy and robustness through extended field tests in indoor and outdoor environments against conventional system. 


\section{References}

[1] S. T. Vater, S. F. Velazquez, and V. J. Cogliano, "A Case Study of Cancer Data Set Combinations for PCBs," Regulatory Toxicology and Pharmacology, vol. 22, pp. 2-10, 8// 1995.

[2] L. Li, T.-C. Chen, Y. Ren, P. I. Hendricks, R. G. Cooks, and Z. Ouyang, "Mini 12, Miniature Mass Spectrometer for Clinical and Other Applications-Introduction and Characterization," Analytical Chemistry, vol. 86, pp. 2909-2916, 2014/03/18 2014.

[3] L. Gao, Q. Song, G. E. Patterson, R. G. Cooks, and Z. Ouyang, "Handheld Rectilinear Ion Trap Mass Spectrometer," Analytical Chemistry, vol. 78, pp. 59946002, 2006/09/01 2006.

[4] A. N. Freedman, "The photoionization detector : Theory, performance and application as a low-level monitor of oil vapour," Journal of Chromatography A, vol. 190, pp. 263-273, 4/4/ 1980.

[5] M. DuBois, K. A. Gilles, J. K. Hamilton, P. A. Rebers, and F. Smith, "Colorimetric Method for Determination of Sugars and Related Substances," Analytical Chemistry, vol. 28, pp. 350-356, 1956/03/01 1956.

[6] Agilent 490 Micro GC Product Information Page; available via the internet at http://www.chem.agilent.com/en-US/products-services/Instruments-Systems/GasChromatography/490-Micro-GC/Pages/default.aspx (accessed July 2014).

[7] Inficon 3000 Micro GC Gas Analyzer Product Information Page; available via the Internet at http://products.inficon.com/en-us/navproducts/Product/Detail/3000_Micro_GC_Gas_Analyzer?path=Products\%2Fpg ChemicalDetection (accessed July 2014).

[8] W. C. Tian, H. K. L. Chan, S. W. Pang, C. J. Lu, and E. T. Zellers, "High sensitivity three-stage microfabricated preconcentrator-focuser for micro gas chromatography," in TRANSDUCERS, Solid-State Sensors, Actuators and Microsystems, 12th International Conference on, 2003, 2003, pp. 131-134 vol.1.

[9] B. Alfeeli and M. Agah, "MEMS-Based Selective Preconcentration of Trace Level Breath Analytes," Sensors Journal, IEEE, vol. 9, pp. 1068-1075, 2009.

[10] T. Wei-Cheng, S. W. Pang, L. Chia-Jung, and E. T. Zellers, "Microfabricated preconcentrator-focuser for a microscale gas chromatograph," Microelectromechanical Systems, Journal of, vol. 12, pp. 264-272, 2003.

[11] M. Agah and K. D. Wise, "Low-Mass PECVD Oxynitride Gas Chromatographic Columns," Microelectromechanical Systems, Journal of, vol. 16, pp. 853-860, 2007.

[12] S. Ali, M. Ashraf-Khorassani, L. T. Taylor, and M. Agah, "MEMS-based semipacked gas chromatography columns," Sensors and Actuators B: Chemical, vol. 141, pp. 309-315, 8/18/2009.

[13] M. A. Zareian-Jahromi, M. Ashraf-Khorassani, L. T. Taylor, and M. Agah, "Design, Modeling, and Fabrication of MEMS-Based Multicapillary Gas Chromatographic Columns," Microelectromechanical Systems, Journal of, vol. 18, pp. 28-37, 2009. 
[14] "Detectors for capillary chromatography," Chemical Analysis, vol. 121, 1992.

[15] S. J. Martin, G. C. Frye, J. J. Spates, and M. A. Butler, "Gas sensing with acoustic devices," in Ultrasonics Symposium, 1996. Proceedings., 1996 IEEE, 1996, pp. 423-434 vol.1.

[16] R. E. Pecsar, R. B. DeLew, and K. R. Iwao, "Performance of a reduced volume thermal conductivity detector," Analytical Chemistry, vol. 45, pp. 2191-2198, 1973/11/01 1973.

[17] S. Zimmermann, S. Wischhusen, and J. Müller, "Micro flame ionization detector and micro flame spectrometer," Sensors and Actuators B: Chemical, vol. 63, pp. $159-166,5 / 15 / 2000$.

[18] S. Narayanan, B. Alfeeli, and M. Agah, "Two-Port Static Coated Micro Gas Chromatography Column With an Embedded Thermal Conductivity Detector," Sensors Journal, IEEE, vol. 12, pp. 1893-1900, 2012.

[19] S. Zampolli, I. Elmi, F. Mancarella, P. Betti, E. Dalcanale, G. C. Cardinali, et al., "Real-time monitoring of sub-ppb concentrations of aromatic volatiles with a MEMS-enabled miniaturized gas-chromatograph," Sensors and Actuators B: Chemical, vol. 141, pp. 322-328, 8/18/ 2009.

[20] C. Cheng, F. Tsow, K. D. Campbell, R. Iglesias, E. Forzani, and T. Nongjian, "A Wireless Hybrid Chemical Sensor for Detection of Environmental Volatile Organic Compounds," Sensors Journal, IEEE, vol. 13, pp. 1748-1755, 2013.

[21] R. A. Iglesias, F. Tsow, R. Wang, E. S. Forzani, and N. Tao, "Hybrid Separation and Detection Device for Analysis of Benzene, Toluene, Ethylbenzene, and Xylenes in Complex Samples," Analytical Chemistry, vol. 81, pp. 8930-8935, 2009/11/01 2009.

[22] W. R. Collin, G. Serrano, L. K. Wright, H. Chang, N. Nuñovero, and E. T. Zellers, "Microfabricated Gas Chromatograph for Rapid, Trace-Level Determinations of Gas-Phase Explosive Marker Compounds," Analytical Chemistry, vol. 86, pp. 655663, 2014/01/07 2013.

[23] Y. Mohsen, H. Lahlou, J.-B. Sanchez, F. Berger, I. Bezverkhyy, G. Weber, et al., "Development of a micro-analytical prototype for selective trace detection of orthonitrotoluene," Microchemical Journal, vol. 114, pp. 48-52, 5// 2014.

[24] Q. Yutao and B. G. Yogesh, "iGC2 : an architecture for micro gas chromatographs utilizing integrated bi-directional pumps and multi-stage preconcentrators," Journal of Micromechanics and Microengineering, vol. 24, p. 065011, 2014.

[25] C. M. M. Almeida and L. V. Boas, "Analysis of BTEX and other substituted benzenes in water using headspace SPME-GC-FID: method validation," Journal of Environmental Monitoring, vol. 6, pp. 80-88, 2004.

[26] M. Akbar and M. Agah, "A Microfabricated Propofol Trap for Breath-Based Anesthesia Depth Monitoring," Microelectromechanical Systems, Journal of, vol. 22, pp. 443-451, 2013.

[27] M. Akbar, D. Wang, R. Goodman, A. Hoover, G. Rice, J. R. Heflin, et al., "Improved performance of micro-fabricated preconcentrators using silica nanoparticles as a surface template," Journal of Chromatography A, vol. 1322, pp. $1-7,12 / 27 / 2013$.

[28] B. Alfeeli, V. Jain, R. K. Johnson, F. L. Beyer, J. R. Heflin, and M. Agah, "Characterization of poly(2,6-diphenyl-p-phenylene oxide) films as adsorbent for 
microfabricated preconcentrators," Microchemical Journal, vol. 98, pp. 240-245, $7 / / 2011$.

[29] H. Shakeel and M. Agah, "Self-Patterned Gold-Electroplated Multicapillary Gas Separation Columns With MPG Stationary Phases," Microelectromechanical Systems, Journal of, vol. 22, pp. 62-70, 2013.

[30] D. Wang, H. Shakeel, J. Lovette, G. W. Rice, J. R. Heflin, and M. Agah, "Highly Stable Surface Functionalization of Microgas Chromatography Columns Using Layer-by-Layer Self-Assembly of Silica Nanoparticles," Analytical Chemistry, vol. 85, pp. 8135-8141, 2013/09/03 2013.

[31] A Guide to Interpreting Detector Specifications for Gas Chromatographs; available via the Internet at https://www.chem.agilent.com/Library/technicaloverviews/Public/59893423EN.pdf (accessed July 2014).

[32] S. Narayanan and M. Agah, "Fabrication and Characterization of a Suspended TCD Integrated With a Gas Separation Column," Microelectromechanical Systems, Journal of, vol. 22, pp. 1166-1173, 2013.

[33] M. Akbar, S. Narayanan, M. Restaino, and M. Agah, "A purge and trap integrated microGC platform for chemical identification in aqueous samples," Analyst, vol. 139, pp. 3384-3392, 2014. 